\title{
Analysis of rock-fall and rock-fall avalanche seismograms in the French Alps
}

\author{
J. Deparis, D. Jongmans, F. Cotton, L. Baillet, F. Thouvenot and D. Hantz \\ Corresponding author: denis.jongmans@ujf-grenoble.fr \\ Laboratoire de Géophysique Interne et Tectonophysique, CNRS, Observatoire de Grenoble, \\ Université Joseph Fourier. \\ Address: LGIT, Maison des Géosciences, BP 53 \\ 38041 Grenoble Cedex 9 France
}

\begin{abstract}
This study reviews seismograms from 10 rock-fall events recorded between 1992 and 2001 by the permanent seismological network Sismalp in the French Alps. A new seismic magnitude scale was defined, which allowed us to compare and classify ground-motion vibrations generated by these Alpine rock-falls. Each rock-fall has also been characterized by its ground-motion duration $t_{30}$ at an epicentral distance of $30 \mathrm{~km}$. No relation was found between rock-fall parameters (fall height, runout distance, volume, potential energy) and rock-fall seismic magnitudes derived from seismogram amplitudes. On the other hand, the signal duration $t_{30}$ shows a rough correlation with the potential energy and the runout distance, highlighting the control of the propagation phase on the signal length. The signal analysis suggests the existence of at least two distinct seismic sources: one corresponding to the initial rupture associated with an elastic rebound during the detachment and the other one generated by the rock impact on the slope. Although the fall phenomenon includes other complex processes (fragmentation of the block, interaction with topography, plastic deformation during and after impact) 2D finite-element simulations of these two seismic sources are able to retrieve the main seismogram characteristics.
\end{abstract}




\section{Introduction}

Rock-fall is the detachment of blocks from a steep slope along a surface on which little or no shear displacement takes place (Cruden and Varnes, 1996). The mass descends by falling, bouncing and/or rolling, with a very rapid to extremely rapid movement. After a free fall with a vertical drop $H_{f}$ from the source rock slope (Figure 1), the falling mass strikes the talus slope and breaks up and/or bounces with a rebound depending on material properties (Giani, 1992; Okura et al, 2000). Lower down, the talus angle diminishes and rock fragments tend to roll. Rock-fall volumes may range from a few $\mathrm{m}^{3}$ to $10^{9} \mathrm{~m}^{3}$ in terrestrial settings (Nicoletti and Sorriso-Valvo, 1991; Corominas, 1996). Small rock-falls are characterized by a more or less independent movement of individual particles (fragmental rockfall; Evans and Hungr, 1993), as opposed to large rock-falls which generate extremely rapid flows of dry debris and usually called rock avalanches (Hsu, 1975; Evans and Hungr, 1993; Cruden and Varnes, 1996). There is no well-defined volume limit and various volume thresholds were proposed for defining rock-falls, from $10^{4} \mathrm{~m}^{3}$ (Hungr et al., 2001) to $10^{5} \mathrm{~m}^{3}$ (Evans and Hungr, 1993). Rock-fall characterization is generally based on a geomorphologic study which gives the main geometrical parameters of the fall: total drop height $\left(H_{t}\right)$, deposit thickness $(T)$ and runout distance $\left(D_{p}\right)$ (Figure 1). These parameters are commonly evaluated from aerial photo or satellite image analysis and/or from field observations. The volume $V$ is generally assessed by multiplying the deposit area $(A)$ by an estimation of average thickness $(T)$. Other sources of information for characterizing rock-falls are the seismograms provided by permanent seismological networks, which are often the only measurements available during the event. Surprisingly, rock-falls - and more generally landslide records - have been little used so far for characterization purposes. We give here a quick (and non exhaustive) review of the studies of seismic waves generated by landslides in general, with a focus on rock-falls.

Berrocal et al. (1978) studied the seismic phases generated by the large $1.310^{9} \mathrm{~m}^{3}$ Mantaro landslide (April 25, 1974), which was widely recorded by seismic observatories, at local and teleseismic distances. They showed that the seismic energy for this $M_{S}=4.0$ event is about $0.01 \%$ of the kinetic energy, which in turn is about $1 \%$ of the potential gravitational energy. To our knowledge, the first detailed study on landslide characterization from seismograms was made by Kanamori and 
Given (1982) and Kanamori et al. (1984) who analyzed seismic signals recorded during the eruption of Mount St. Helens (May 18, 1980). They concluded that the long-period seismic source can be represented by a nearly horizontal single force with a characteristic time constant of $150 \mathrm{~s}$ and that this single force is due to the massive $2.510^{9} \mathrm{~m}^{3}$ landslide affecting the north slope of Mount St. Helens. Other studies performed by Kanamori and co-authors on massive landslides (Eissler and Kanamori, 1987; Hasegawa and Kanamori, 1987; Brodsky et al., 2003) confirmed that the long period seismic radiation is better simulated using a nearly horizontal single force rather than a double couple. Later, Dahlen (1993) interpreted landslides as shallow horizontal reverse faults and showed that the seismic source can, in the long-wavelength limit, be represented by a moment tensor which reduces to a horizontal surface point force if the shear-wave velocity within the sliding block is significantly lower than the one of the slope. Weichert et al. (1994) examined the seismic signatures of the 1990 Brenda Mine collapse $\left(V=210^{6} \mathrm{~m}^{3}\right)$ and of the 1965 Hope rockslides $\left(V=4710^{6} \mathrm{~m}^{3}\right)$, with a focus on the differentiation between seismic signals from landslides and real earthquakes. They suggested a longperiod/short-period discriminant $\left(M_{S}\right.$ versus $m_{b}$ seismic magnitudes) and they observed a correlation between the efficiency of potential to seismic energy conversion with the slope of the slide detachment. Very low efficiency (about $10^{-6}$ ) was obtained when using Richter's (1958) energy equation. For the Hope events, they observed two phases on the long-period records, that they interpreted as the initial down hill thrust, followed one-half minute later by the impact on the opposite valley side. La Rocca et al. (2004) analyzed the seismic signals produced by two landslides that occurred with a delay of 8 minutes at the Stromboli volcano on 30 December 2002, with volumes of about $1310^{6} \mathrm{~m}^{3}$ and $710^{6} \mathrm{~m}^{3}$. Both landslides generated complex seismic signals with an irregular envelope, a frequency range between 0.1 and $5 \mathrm{~Hz}$ and duration of a few minutes. Comparing the observed low-frequency seismograms with synthetic signals, La Rocca et al. (2004) estimated the magnitude of the force exerted by the sliding mass, from which they inferred the landslide volumes. Compared to the works on massive rockslides, studies of rock-fall seismic signals have been very few. Norris (1994) reviewed seismograms from 14 rock-falls and avalanches of moderate to large volumes $\left(10^{4}\right.$ to $\left.10^{7} \mathrm{~m}^{3}\right)$ at Mount St. Helens, Mount Adams and Mount Rainier in the Cascade Range. At Mount St Helens, the analysis of 5 rock-falls $\left(10^{4}\right.$ to $\left.10^{6} \mathrm{~m}^{3}\right)$ suggested a consistent increase in 
seismogram amplitude with the volume of rock-falls having the same source area and descent paths. On the contrary, rock-fall sequences or smaller rock-falls, such as those studied earlier at Mount St. Helens (Mills, 1991) and Makaopuhi Crater (Tilling et al., 1975), show a poor correlation between signal amplitude/duration and volume. In the conclusions, the authors stressed the importance of seismic networks for detecting large mass movements. In Yosemite Valley, the records of the July, 10, 1996 Happy Isles rock-fall were studied by Uhrhammer (1996) and Wieczorek et al (2000). They found that the prominent seismic phases ( $P, S$ and Rayleigh waves) are consistent with two rock impacts 13.6 seconds apart and they calculated a seismic $M_{L}$ magnitude of 1.55 and 2.15 for these two events. In order to test the feasibility of monitoring rock-falls with seismic methods in Yosemite Valley, Myers et al (2000) deployed a network of five stations in the late summer and fall of 1999. They concluded that monitoring using seismic records was theoretically feasible and that an event with equivalent earthquake magnitude of 2.6 would be located. However, the detection of rock-fall-related events was not verified. In a recent paper reviewing rock-falls and rock avalanches that occurred in 1991 and 1996 in Mount Cook National Park (New Zealand), McSaveney (2002) displayed several seismograms recorded during these events at distances between $31 \mathrm{~km}$ and $190 \mathrm{~km}$. He used these signals for providing an estimate of rock-fall duration but no attempt was made to link the seismic parameters to the rock-fall geometric properties or to give a quantitative distribution of mass collapse over time.

This introduction illustrates the attempts and the difficulty of extracting relevant information on landslide characteristics from seismic signals. Compared to previous works, our study is focused on rock-falls and rock-fall avalanches, and particularly on those that occurred in the Alps between 1992 and 2001 and were recorded by the French permanent seismological network Sismalp (Thouvenot et al., 1990; Thouvenot and Fréchet, 2006).

The aims of this paper are fourfold: (i) to evaluate the ability of this network to detect rock-falls in the western Alps, (ii) to identify the seismic parameter(s) which could characterize rock-falls and help in classifying them, (iii) to establish the relation (if any) between the seismic parameters and the geometric characteristics of rock-falls and (iv) to identify the seismic sources appearing in the signals and to study the potential link between them and the different phases of a rock-fall (detachment, 
impact, rolling and/or sliding). In a first step, we try to obtain simple relations between seismic and rock-fall parameters, in order to determine the potentiality of seismic parameters for rock-fall characterization. In the second part of the study, we use signal-processing techniques and 2dimensional numerical modeling for interpreting the different seismic phases appearing within the seismograms.

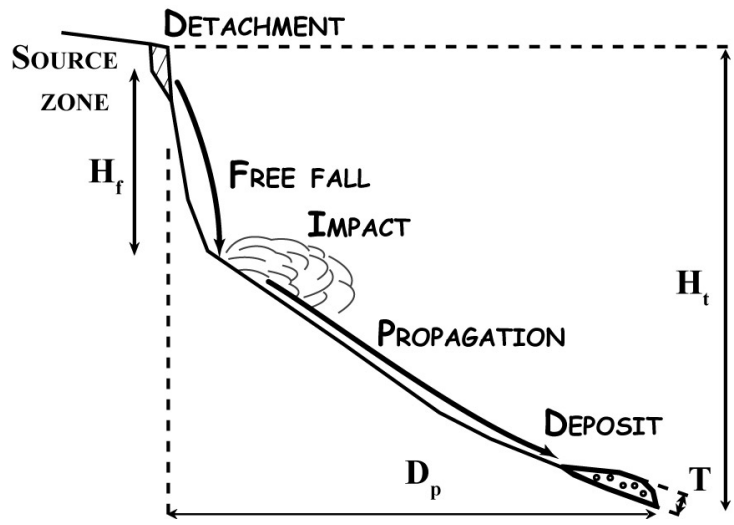

Figure 1. Schematic cross-section of a rock-fall path profile. $H_{f}$ is the vertical free-fall height of the center of gravity, $H_{t}$ is the total drop height, $D_{p}$ is the runout distance and $T$ is the average thickness of the deposit.

\section{Rock-fall location and characteristics}

Rock-falls with a volume larger than $10^{3} \mathrm{~m}^{3}$, which occurred in the western Alps during the 19922001 period, were extracted from different inventories (BRGM database www.bdmvt.net/; Frayssines and Hantz, 2006) and cross-checked with data from the Alpine permanent seismological network (Sismalp). The Sismalp project, launched in 1987, aimed at deploying a network of several tens of automatic seismic stations in south-eastern France, from Lake Geneva to Corsica (Thouvenot et al., 1990). In its present state, the network consists of 44 stations which monitor the seismic activity over an area covering around 70,000 $\mathrm{km}^{2}$ with distances between stations of about $30 \mathrm{~km}$ (Thouvenot and Fréchet, 2006). All the stations of the network are equipped with 1-Hz Mark-Product $\mathrm{L} 4 \mathrm{C}$ velocimeters, ten of which are three-component instruments. At each station, a microprocessor scans the digital signal, and, whenever a detection criterion is met, the corresponding signal is stored in memory. The equipment used at the turn of the 1980s allowed the storage of six 40 -sec signals only. Upgraded at the end of the 1990s, it can now store hundreds of triggered signals, each up to 4-min 
long. Stations are connected to the switched telephone network and are dialed every night from a central station at the Grenoble Observatory. Any earthquake with an $M_{L}$-magnitude larger than about 1.3 can be detected and located (two events per day on average); the location precision on the hypocenter is high, with horizontal uncertainties smaller than $1 \mathrm{~km}$ for $M_{L}>2$ events.

Only events recorded by at least three seismic stations were considered in this study. Figure 2 shows the location of the 10 selected rock-falls and rock-fall avalanches ( $R 1$ to $R 10)$ and of the 39 Sismalp seismological stations (out of a total of 44) installed north of the $44^{\circ} \mathrm{N}$ parallel. Two events (Rl, La Palette, and R10, La Dent du Loup) are located $15 \mathrm{~km}$ north-west of Grenoble, six (R2, Versaire, and $R 5$ to $R 9$, Saint-Antoine valley) are clustered 30 to $40 \mathrm{~km}$ east of Grenoble, and the remaining two occurred near the Swiss and Italian borders (R6, Les Drus) or in Switzerland (R3, Sandalp). Eight rock-falls ( $R 1, R 3$ and $R 5$ to $R 10)$ occurred in limestone, one in amphibolite $(R 2)$ and one in granite (R4). All sites exhibit near vertical slopes (over $70^{\circ}$ ) in or under the source zone, which implies a free-fall phase during the movement (Cruden and Varnes, 1996).

The main characteristics of the 10 rock-fall events are listed in Table 1 . They were obtained from international publications $(R 1, R 3, R 10)$ and unpublished geotechnical reports $(R 2, R 4, R 5$ to $R 9)$. Fall volumes vary over a wide range from $210^{3} \mathrm{~m}^{3}$ to $1.7510^{6} \mathrm{~m}^{3}$, for total drop heights between 270 and $820 \mathrm{~m}$ and run out distances between 190 and $1300 \mathrm{~m}$.

The La Palette rock-fall (event $R 1$ ) occurred in the upper part of a $250 \mathrm{~m} \mathrm{high,} 70^{\circ}$ dipping cliff composed of thick limestone beds dipping $10^{\circ}$ to $30^{\circ}$ transversely to the slope (Frayssine and Hantz, 2006). The initial failure mechanism is a slide along a $45^{\circ}$ dipping joint; the sliding mass $\left(210^{4} \mathrm{~m}^{3}\right)$ fell $170 \mathrm{~m}$ down to the underlying $50^{\circ}$ to $30^{\circ}$ dipping marly slope, where it propagated up to $450 \mathrm{~m}$ from the failure scarp. The Versaire rock-fall $(R 2)$ occurred in the upper part of a $150 \mathrm{~m}$ high, $70^{\circ}$ dipping cliff, made of massive amphibolite. The initial failure mechanism is a slide; the sliding mass $\left(510^{4} \mathrm{~m}^{3}\right)$ fell $100 \mathrm{~m}$ down to the underlying $50^{\circ}$ dipping amphibolite slope, where it propagated up to $250 \mathrm{~m}$ from the failure scarp. The Sandalp rockfall $(R 3)$ took place in the middle part of a $700 \mathrm{~m}$ high rock wall, which consists in thick near-horizontal limestone beds (Keusen, 1998). The rock mass (1.75 $10^{6} \mathrm{~m}^{3}$ ) initially slid on $45^{\circ}$ dipping schistosity planes, jumped over a $100 \mathrm{~m}$ high, $80^{\circ}$ dipping cliff, moved on a $35^{\circ}$ dipping limestone slope and stopped in the valley with a runout distance of $1300 \mathrm{~m}$. 
Due to the intense schistosity of the rock mass, an important part of the avalanche deposit consists in fine particles. The Drus rockfall ( $R 4$; Ravanel and Deline, 2006) took place in the middle part a $700 \mathrm{~m}$ high, $75^{\circ}$ dipping granite wall, in the Mont Blanc Massif. The failure mechanism might have been topple or slide and the drop height reached $450 \mathrm{~m}$. Between January 1998 and June 1999, five rockfalls ( $R 5$ to $R 9$ ) affected a $500 \mathrm{~m}$ high cliff made of thin folded limestone beds, in the SaintAntoine valley. Volumes ranged from $310^{4}$ to $110^{5} \mathrm{~m}^{3}$. They occurred at different heights in the middle part of the cliff which dips $70^{\circ}$. The first two rockfalls ( $R 5$ and $R O$ ) involved tall columns with beds dipping opposite to the slope. The failure mechanisms might have been topple or slide, with a fall height of $90 \mathrm{~m}$ to $100 \mathrm{~m}$. The three following ones ( $R 7$ to $R 9$ ) were located higher in the cliff (fall height of $190 \mathrm{~m}$ ) and were slides along bedding planes, steeply dipping towards the slope. The fallen masses then propagated on a slope made of marl and limestone thin layers, whose slope angle decreases from $65^{\circ}$ to $25^{\circ}$. Finally, the Dent du Loup rockfall $(R 10)$ occurred in a $200 \mathrm{~m}$ high, $70^{\circ}$ dipping cliff, made of thick limestone beds dipping $10^{\circ}$ to $30^{\circ}$ opposite to the slope (Frayssines and Hantz, 2006). The initial failure mechanism is a stepped slide on $75^{\circ}$ dipping joints. The sliding mass $\left(210^{3} \mathrm{~m}^{3}\right)$ then fell down to the underlying $35^{\circ}$ dipping scree slope, where it propagated up to $300 \mathrm{~m}$ from the failure scarp.

All these rock failures took place in a steep cliff (with a slope of at least $70^{\circ}$ ) and were followed by a free-fall phase. Considering the volume threshold $\left(10^{4} \mathrm{~m}^{3}\right)$ proposed by Hungr et al. (2001), all these events should be classified as rock avalanches, except the Dent du Loup rock-fall (R10) whose size (2 $10^{3} \mathrm{~m}^{3}$ ) is too small. However, 8 of the events have a volume between $10^{4} \mathrm{~m}^{3}$ and $10^{5} \mathrm{~m}^{3}$ which is the other threshold proposed by Evans and Hungr (1993). Thus, the limits between a rock-fall and a rock avalanche cannot be defined precisely, as the interactions between the blocks progressively increase with the number of blocks and the volume. Only the Sandalp event $(R 3)$ can be unambiguously classified as rock avalanche. For simplicity's sake, we will use the general term rock-fall in the following, except when specifically discussing the mechanisms (fragmental rock-fall or rock-fall avalanche). 


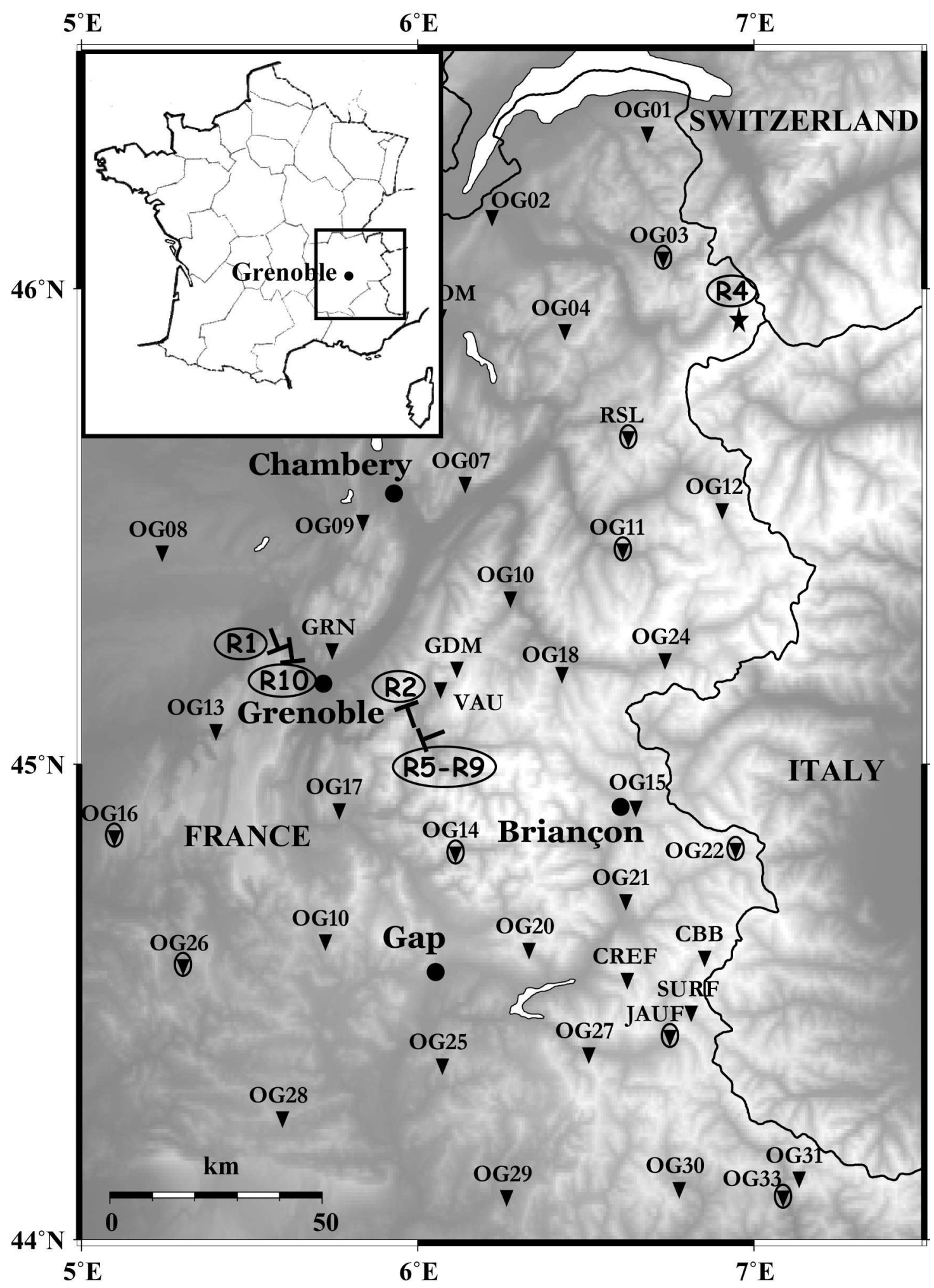

Figure 2. Location of the selected rock-falls $R 1$ to $R 10$ (T symbol and star), and of the Sismalp seismic stations (triangles for vertical component, triangles into circles for $3 \mathrm{C}$ stations). The $\mathrm{T}$ symbol indicates rock-fall propagation directions when known. $R 3$ is located in Switzerland out of this map (see Table 1) 


\begin{tabular}{|c|c|c|c|c|c|c|c|c|c|c|c|c|c|}
\hline \multirow{2}{*}{$\begin{array}{l}\text { DATE } \\
\text { (GMT) }\end{array}$} & \multicolumn{2}{|c|}{ LOCATION } & \multirow[b]{2}{*}{$\mathbf{N}_{\mathrm{s}}$} & \multirow[b]{2}{*}{ EVENT } & \multirow{2}{*}{$\mathbf{V}\left(\mathbf{m}^{3}\right)$} & \multirow{2}{*}{$\begin{array}{c}\boldsymbol{H}_{f} \\
(\mathbf{m})\end{array}$} & \multirow{2}{*}{$\begin{array}{c}D_{p} \\
(\mathbf{m})\end{array}$} & \multirow{2}{*}{$\begin{array}{r}\mathbf{H}_{\mathbf{t}} \\
(\mathbf{m})\end{array}$} & \multirow{2}{*}{$\begin{array}{c}E_{p} \\
(\mathbf{G J})\end{array}$} & \multirow[b]{2}{*}{$M_{L}$} & \multirow[b]{2}{*}{$M_{r f}$} & \multirow{2}{*}{$\begin{array}{c}E_{s} \\
(\mathbf{M J})\end{array}$} & \multirow{2}{*}{$E_{s} / E_{p}$} \\
\hline & $\begin{array}{l}\text { Longitude } \\
\text { (E) }\end{array}$ & $\begin{array}{l}\text { Latitude } \\
\text { (N) }\end{array}$ & & & & & & & & & & & \\
\hline \begin{tabular}{|c|} 
20/04/1992 \\
$07: 07: 14$
\end{tabular} & $5^{\circ} 58$ & $45^{\circ} 24$ & 4 & $R 1$ & 20000 & 170 & 450 & 450 & 85 & 1.2 & 1.5 & 10.8 & 1.27E-04 \\
\hline $\begin{array}{c}28 / 03 / 1995 \\
14: 24: 18\end{array}$ & $5^{\circ} 96$ & $45^{\circ} 12$ & 15 & $R 2$ & 50000 & 100 & 250 & 270 & 125 & 1.6 & 1.8 & 26.2 & 2.09E-04 \\
\hline $\begin{array}{c}\text { 03/03/1996 } \\
18: 30: 59\end{array}$ & $8^{\circ} 65$ & $46^{\circ} 46$ & 7 & $R 3$ & 1750000 & 150 & 1300 & 800 & 6560 & 2.8 & 2.1 & 84.4 & $1.29 \mathrm{E}-05$ \\
\hline $\begin{array}{c}17 / 09 / 1997 \\
23: 23: 20\end{array}$ & $6^{\circ} 95$ & $45^{\circ} 93$ & 12 & $R 4$ & 14000 & 450 & 450 & - & 158 & 1.7 & 1.8 & 27.4 & $1.74 \mathrm{E}-04$ \\
\hline \begin{tabular}{|c|}
$22 / 01 / 1998$ \\
$14: 58: 09$
\end{tabular} & $6^{\circ} 01$ & $45^{\circ} 05$ & 9 & $R 5$ & 100000 & 90 & 995 & 780 & 225 & 0.9 & 1.2 & 4.4 & $1.93 E-05$ \\
\hline $\begin{array}{c}\text { 22/01/1998 } \\
15: 07: 00\end{array}$ & $6^{\circ} 01$ & $45^{\circ} 05$ & 11 & $R 6$ & 100000 & 100 & 880 & 780 & 250 & 1.2 & 1.5 & 9.9 & 3.98E-05 \\
\hline $\begin{array}{c}29 / 06 / 1998 \\
13 / 06 / 35\end{array}$ & $6^{\circ} 01$ & $45^{\circ} 05$ & 21 & $R 7$ & 65000 & 190 & 940 & 820 & 309 & 1.6 & 1.6 & 17.8 & $5.76 \mathrm{E}-05$ \\
\hline \begin{tabular}{|c|}
$30 / 06 / 1998$ \\
$20: 42: 56$ \\
\end{tabular} & $6^{\circ} 01$ & $45^{\circ} 05$ & 10 & $R 8$ & 35000 & 190 & 940 & 820 & 166 & 1.3 & 1.5 & 9.3 & $5.60 \mathrm{E}-05$ \\
\hline $\begin{array}{c}\text { 08/06/1999 } \\
\text { 22:33:39 }\end{array}$ & $6^{\circ} 01$ & $45^{\circ} 05$ & 11 & $R 9$ & 30000 & 190 & 190 & 820 & 143 & 1.1 & 1.4 & 8.1 & 5.71E-05 \\
\hline $\begin{array}{c}\text { 04/01/2001 } \\
23: 37: 47\end{array}$ & $5^{\circ} 62$ & $45^{\circ} 22$ & 3 & $R 10$ & 2000 & 130 & 300 & 270 & 6,5 & 1.2 & 1.5 & 11.3 & $1.74 \mathrm{E}-03$ \\
\hline
\end{tabular}

Table 1. Characteristics of the ten selected rock-fall events. $N_{s}$ is the number of stations having recorded signals. $V$ is the volume, $H_{f}$ is the vertical free-fall height of the center of gravity, $D_{p}$ is the runout distance, $H_{t}$ is the total drop height, $E_{p}$ is the initial potential energy $\left(\rho V g H_{f}\right), M_{L}$ is the local seismic magnitude, $M_{r f}$ is the new rock-fall seismic magnitude and $E_{s}$ is the seismic energy derived from equation (4).

These rock-falls were recorded by a number of stations varying between 3 and 21, with distances ranging from $10 \mathrm{~km}$ to a maximum of $250 \mathrm{~km}$. Distances between the events and the closest station are usually between 10 and $25 \mathrm{~km}$. 


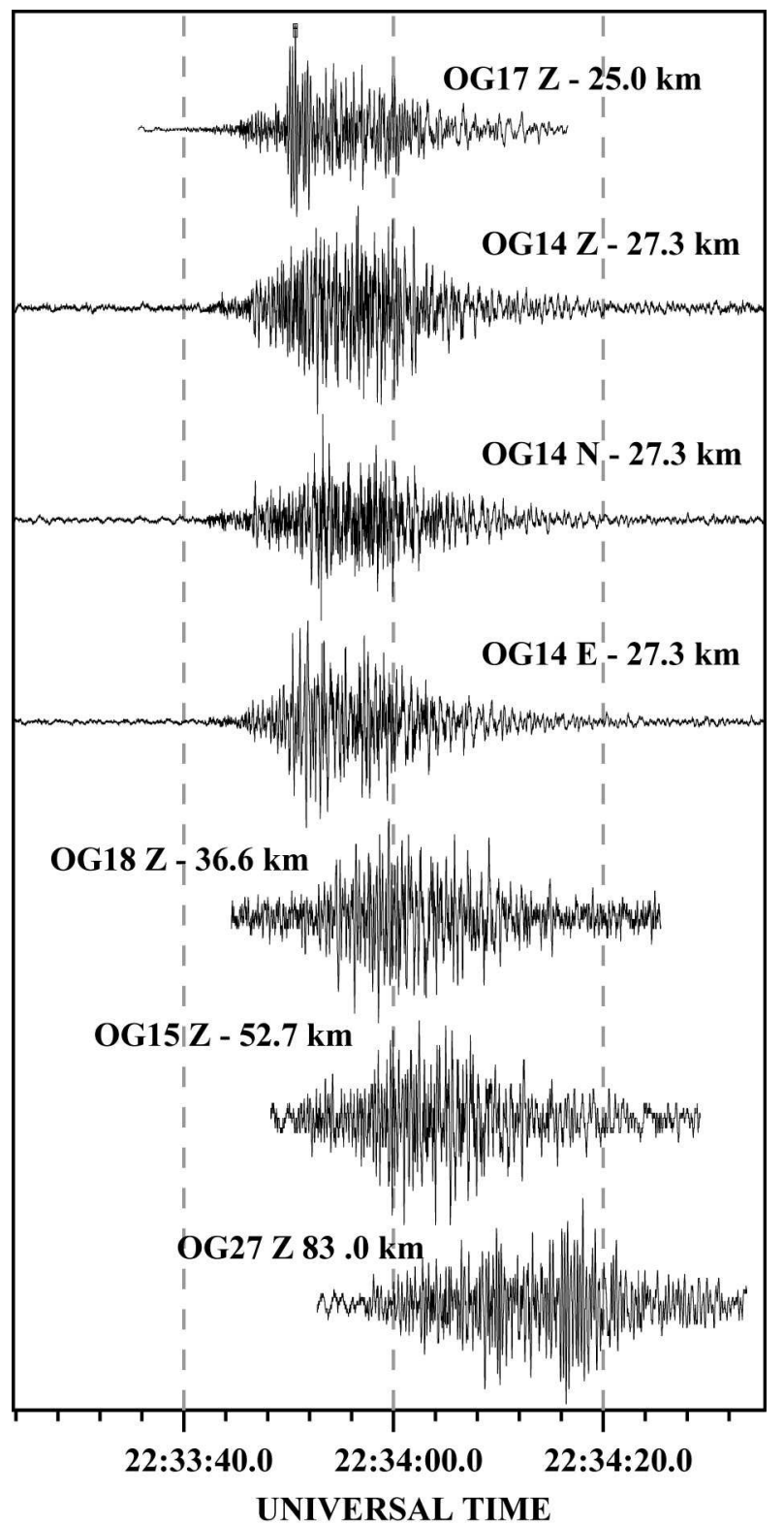

Figure 3. Signals of the $R 9$ event displayed for the 5 closer stations of the Sismalp network at epicentral distances between 25 and $83 \mathrm{~km}$. Amplitudes are normalized for each station. Stations shown here are equipped with vertical-component seismometers, except station $O G 14$ (three component seismometers).

Figure 3 shows seismograms recorded during event $R 9$ for five distances from 25 to $83 \mathrm{~km}$. One can observe the quick degradation of the signal-to-noise ratio with the epicentral distance, resulting from the strong attenuation in shallow crustal layers. In Figure 4 are plotted the vertical seismograms and the displacement Fourier spectra of the 10 events for the nearest records. The seismograms exhibit various and complex waveform shapes from one event to the other, with emergent beginnings and 
several late energetic phases that we will attempt to interpret further in this paper. The corner frequency of the spectra, marked by an arrow in Figure 4, is always close to $1 \mathrm{~Hz}$ whatever the event, showing that $1-\mathrm{Hz}$ velocimeters only record the high-frequency part of ground motion. These results support the deployment of broad-band seismometers for analyzing the frequency content of rock-fall signals.

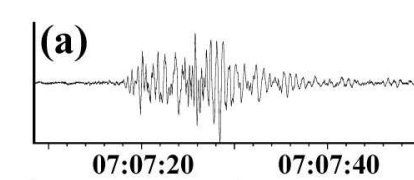

(b)

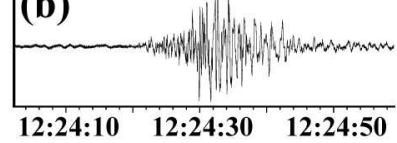

(c)
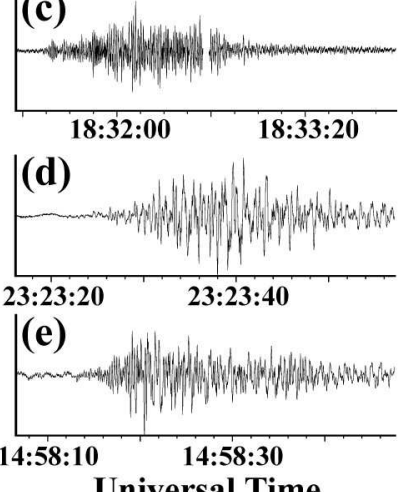

Universal Time
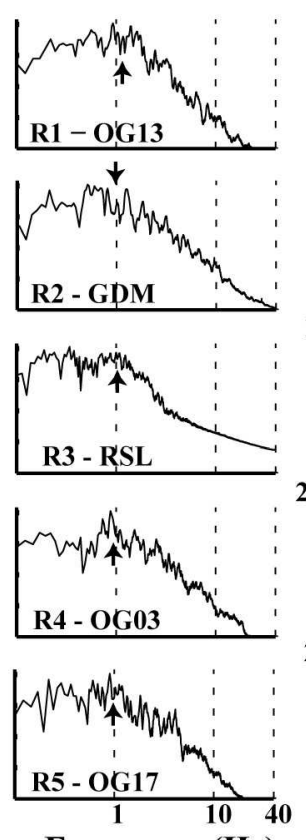

Frequency $(\mathrm{Hz})$
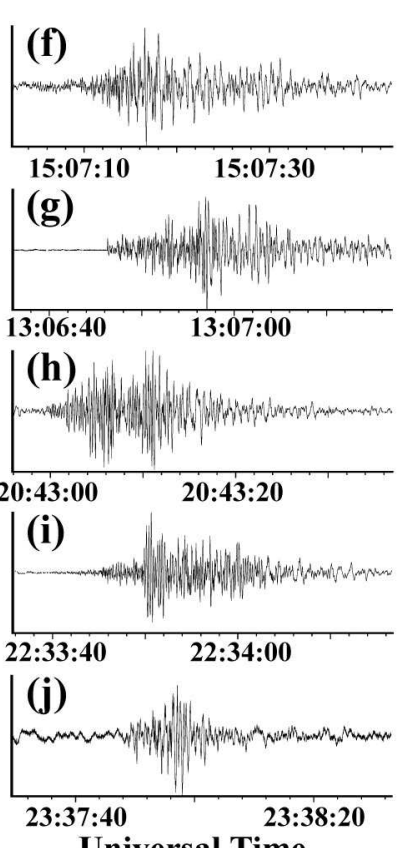

Universal Time

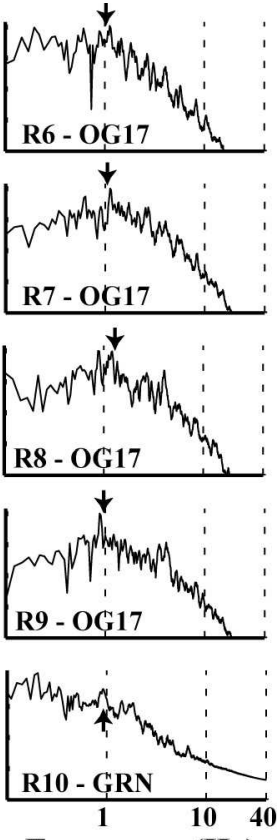

Frequency (Hz)

Figure 4. Vertical seismograms and corresponding displacement Fourier spectra measured at the closest station for the 10 events $R 1$ to $R 10$. The time scale is different for each record. Arrows indicate corner frequencies.

Table 1 lists location and characteristics for the 10 events. The free-fall drop height $\left(H_{f}\right)$ varies from 90 to $450 \mathrm{~m}$ and the potential energy values $\left(E_{p}\right)$ values are between 6.5 and $6560 \mathrm{GJ}$ for volumes ranging from $210^{3}$ to $1.7510^{6} \mathrm{~m}^{3}$. Table 1 also includes local seismic-magnitude values $\left(M_{L}\right)$ provided by the Sismalp network, using the Richter empirical model (1958). These values are between 0.9 and 2.8. Except for event $R 3\left(M_{L}=2.8\right)$, other rock-falls have low magnitudes $(0.9-1.7)$, actually very close to -and sometimes beyond- the lowest magnitude detectable by the network, estimated to $M_{L}=1.3$ and twice lower than the one assessed for the network deployed in the Yosemite valley (Myers et al., 2000). Moreover, locating rock-falls with emergent $\mathrm{P}$ onsets and unclear S onsets is a 
challenge difficult to face by a seismic network, although other types of seismic arrays such as antennas might have better capabilities in this respect. The limited number of observed events (10) and of the corresponding records (103 in totals) partly results from the relative sparseness of the stations and from the wave attenuation in the upper crust. However, as pointed out by Weichert et al. (1994) and suggested by the low $M_{L}$ values in Table 1, the poor efficiency of potential to seismic energy conversion is probably a significant limiting factor, the effect of which will be addressed further in this paper.

\section{Seismic record analysis and rock-fall seismic magnitude scale}

Our aim is to characterize rock-falls from the analysis of the recorded seismograms. In this part, the event is treated as an entity (we do not separate the detachment, impact and propagation phases) in order to have a global characteristic. The first option is to compare rock-falls in terms of seismic magnitude, in a way similar to what was done for earthquakes. The $M_{L}$ magnitude scale was defined from the maximum recorded displacement (Richter, 1935 and 1958), for segregating large, moderate and small shocks. The relation between the maximum seismographic amplitudes for a given shock at various epicentral distances was empirically built and it was assumed that the ratio of the maximum amplitudes registered by similar instruments at equal epicentral distances for two given shocks is a constant. Richter then defined the $M_{L}$ magnitude as the logarithm of the ratio of the amplitude of the given shock to that of a standard shock at the same epicentral distance. The standard shock (seismic magnitude equal to 0) was arbitrary defined as an earthquake for which the maximum displacement (in millimeter) recorded on a standard Wood-Anderson seismometer is equal to one micrometer at $100 \mathrm{~km}$. The so-called Richter attenuation law for distances between 25 and $600 \mathrm{~km}$ was published in 1935 by Richter. Kradolfer and Mayer-Rosa (1988) showed that this law satisfactorily fitted the observed amplitude decay for earthquakes in the Alps, and it is currently used by Sismalp to compute $M_{L}$ magnitudes (Thouvenot et al., 2003).

For defining a seismic magnitude scale for rock-falls, it is first necessary to determine the relation between the maximum seismographic amplitudes of a given rock-fall at various distances. Due to the 
small number of available events and records (67 vertical-component records), the following simple attenuation relationship was used (Ambraseys et al, 1996; Gasperini, 2002; Berge-Thierry et al, 2003):

$$
\log _{10}(P G D)=b+b_{m} M_{l}+b_{r} \log _{10}(r) \pm \sigma
$$

where $P G D$ is the peak ground displacement, $M_{L}$ the local seismic magnitude, $r$ the epicentral distance $(\mathrm{km})$ and $\sigma$ the standard deviation. Parameters $b, b_{m}$ and $b_{r}$ are empirical coefficients determined from the linear regression on the values of peak displacements and epicentral distances. In this relation, we propose that the $M_{L}$ magnitude is replaced with $M_{r f}$, which will be called the rock-fall seismic magnitude. In order to both determine the attenuation model coefficients of equation (1) and the seismic magnitude, an iterative scheme was applied. In a first step, rock-fall seismic magnitudes $M_{r f}$ are approximated by $M_{L}$ magnitudes and the coefficients $b,\left(b_{m} M_{r f}\right)$ and $b_{r}$ are determined by fitting equation (1) to the data. Using Richter's original definition of an $M_{L}=0$ shock, $M_{r f}$ values have been computed from the $\left(b_{m} M_{r f}\right)$ terms. Equation (1) is then updated with these new $M_{r f}$ values. The iterative process is stopped when the $R M S$ difference between two iterations is stable. The attenuation relation obtained for rock-falls is given by:

$$
\log _{10}(P G D)=-1.58[ \pm 0.39]+1.00[ \pm 0.27] \times M_{r f}-0.94[ \pm 0.18] \times \log _{10}(r) \pm 0.21
$$

where the seismic magnitude $M_{r f}$ is defined as the logarithm of the ratio of the amplitude for the given rock-fall to that of the standard rock-fall at the same epicentral distance. The $95 \%$ prediction interval bands for each parameter are indicated between brackets. The peak ground displacements as a function of distance are shown in Figure 5a for the 10 rock-falls. In the same graphs are plotted the Richer attenuation laws derived for the $M_{L}$ magnitude values. In Figure 5b, the new attenuation relation is compared to corrected displacement data and to the corresponding Richter attenuation law. The amplitude decay for some rock-falls $(R 5, R 6, R 8, R 9$ and $R 10)$ significantly differs from the Richter attenuation curve used for earthquake characterization. This highlights the expected predominance of surface waves generated by rock-falls. $M_{r f}$ and $M_{L}$ values are given for the 10 rockfalls in Table 1. $M_{r f}$ values exhibit a narrower range (1.2 to 2.1) compared to $M_{L}$ values (0.9 to 2.8), due to the smaller slope of the attenuation model. 


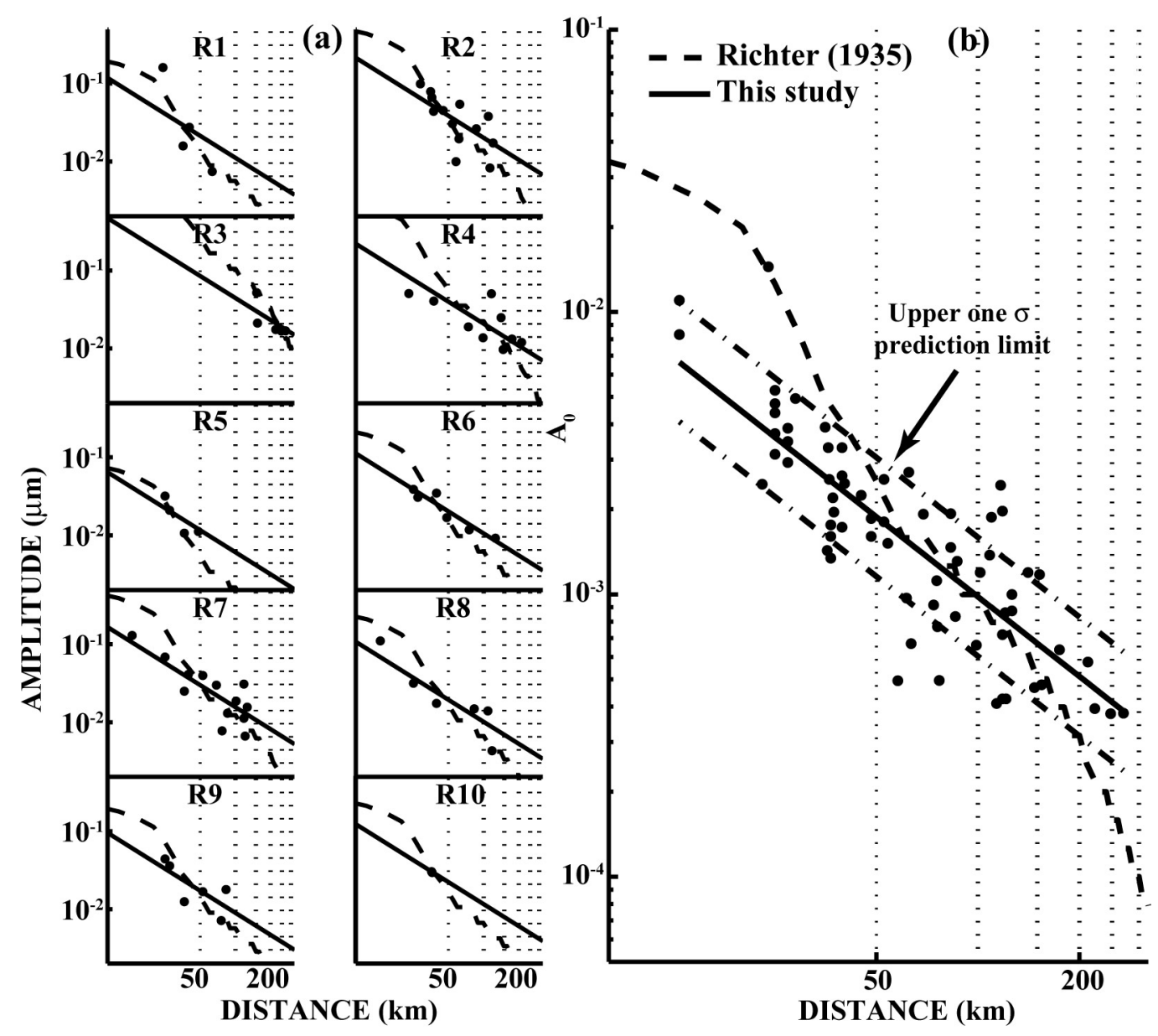

Figure 5. (a) Comparison between vertical displacement amplitude-distance graphs for the ten rockfalls, the Richter attenuation model (dashed line) and the new attenuation relation proposed for rockfalls (solid line) (b) Vertical displacement values as a function of epicentral distances, for the 10 rockfalls. Displacement values are corrected by the seismic magnitude using equation (2) and compared to the Richter attenuation model (dashed line) and to the new median model (solid line) plotted with one standard deviation bounds (dot-dashed lines).

As the corner frequency of the displacement spectra has been shown to be an unreliable source parameter (Figure 4), due to the frequency cut-off of the short-period seismometers, we investigate the possibility of using the signal duration for characterizing and discriminating the rock-falls. The ground-motion duration was computed for all rock-fall seismograms, following the definition (Trifunac and Brady, 1975) which is the time interval between the points at which 5\% and 95\% of the total energy has been recorded. Figure 6 shows the duration-distance graphs for the 10 events in a bi- 
logarithmic diagram, for distances shorter than $100 \mathrm{~km}$. The 40 -sec record length on most Sismalp stations was too small to measure the signal duration for the high-volume event $(R 3)$. For events $R 10$, only three stations exhibit a good signal-to-noise ratio. Data for the remaining 8 events show a regular increase of the duration with the epicentral distance, resulting from the propagation of waves at different velocities and from diffusion in the crust. A theoretical relation (equation (3)) was fitted to each data set and the regression parameters $a_{1}$ and $a_{2}$ are given in Table 2, with their $95 \%$ prediction interval bands.

$$
\log _{10}(t(r))=a_{1}+a_{2} \log _{10}(r)
$$

\begin{tabular}{|c|c|c|c|c|c|}
\hline EVENT & $a_{1}$ & 95\% P.I. & $a_{2}$ & 95\% P.I. & $t_{30}(\mathrm{~s})$ \\
\hline R1 & -0.09 & \pm 3.1 & 0.85 & \pm 1.01 & 16.6 \\
\hline $\mathbf{R 2}$ & 1.60 & \pm 0.68 & $\mathbf{0 . 3 7}$ & \pm 0.18 & 17.7 \\
\hline R4 & 2.09 & \pm 1.71 & 0.29 & \pm 0.5 & 21.3 \\
\hline R5 & 2.07 & $\pm \mathbf{3 . 1 3}$ & 0.35 & \pm 1.08 & 26.2 \\
\hline R6 & 1.55 & \pm 3.13 & 0.42 & \pm 0.12 & 19.6 \\
\hline R7 & 2.74 & \pm 0.46 & 0.1 & \pm 0.32 & 22.1 \\
\hline R8 & 1.7 & \pm 1.12 & 0.35 & \pm 0.34 & 18.0 \\
\hline R9 & 1.41 & \pm 1.00 & 0.41 & \pm 0.26 & 16.7 \\
\hline $\begin{array}{c}\text { All } \\
\text { events }\end{array}$ & 1.82 & \pm 0.35 & 0.33 & \pm 0.09 & 19.4 \\
\hline
\end{tabular}

Table 2: Regression parameters $a_{1}$ and $a_{2}$ of equation (3), with their corresponding $95 \%$ prediction interval, computed for the 8 valuable rock-falls (see text for details), and corresponding $t_{30}$ values.

The slope parameter $a_{2}$ varies between 0.1 and 0.85 . The $a_{2}$ values with reasonable prediction interval bands are between 0.35 and 0.42 . A value of 0.33 was found considering all events. As most signals were recorded in the 20 - to $40-\mathrm{km}$ distance range, each rock-fall was characterized by the ground-motion duration $t_{30}$ computed at an epicentral distance of $30 \mathrm{~km}$ using equation (3). This value, which is calculated with the global total energy recorded on seismogram, includes all the phases of rock-falls: detachment, impact and propagation of the mass. Values of $t_{30}$ given in Table 2 will be discussed in the next section. 


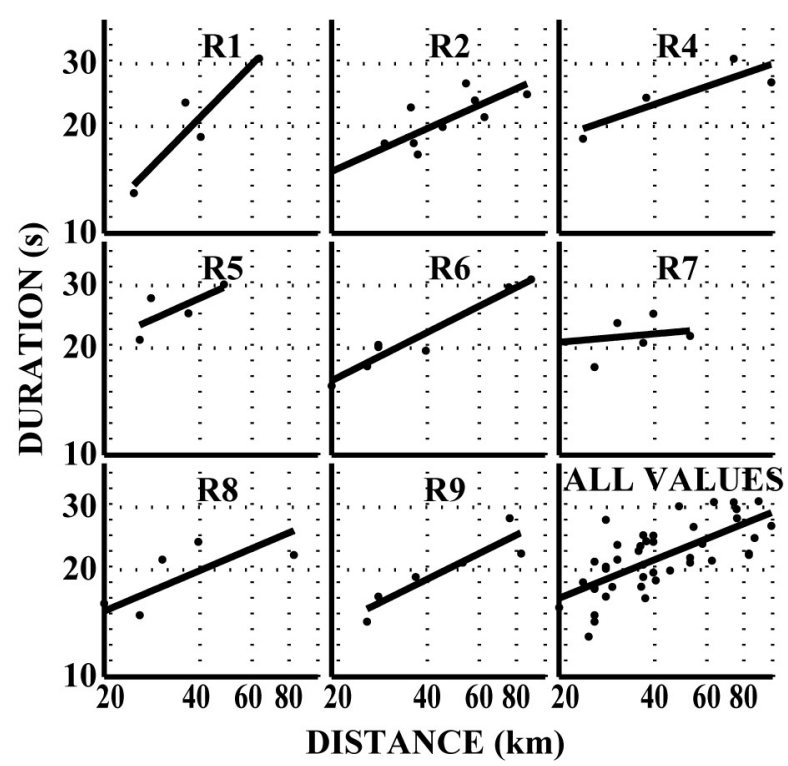

Figure 6. Record duration as a function of the epicentral distance $r$ for rock-falls recorded by at least 4 stations.

\section{Comparison between seismic and rock-fall characteristics}

Despite the few recorded rock-falls, we attempt to link the measured ground motion characteristics (rock-fall seismic magnitude, seismic energy and duration) to the rock-fall parameters (fall height $H_{f}$, runout $D_{p}$, volume $V$, and potential energy $\left.E_{p}\right)$.

Seismic energy for landslides is hard to assess from seismic records, as it depends on the radiation pattern which is generally unknown. This difficulty and the scarcity of records explain why previous works on energy calculation used the formulas established for earthquakes. Wiechert et al. (1994) considered Richter's formulas for deriving the seismic energy released by several landslides from $M_{S}$ and $M_{L}$. In this study, we applied Kanamori's (1977) equation.

$$
\log _{10} E_{s}=1.5 M_{s}+4.8
$$

where $E_{s}$ is in joules and $M_{s}$ is the surface wave magnitude. $M_{s}$ was replaced by $M_{r f}$ for computing $E_{s}$ values for the 10 rock-falls given in Table 1 . This relation is very close to the one proposed by Richter (1958) from surface waves.

Figure 7 compares in a systematic way the 3 ground-motion and the 4 rock-fall characteristics. As $E_{s}$ and $M_{r f}$ are linked, they are plotted in the same graphs with different ordinate values. The comparison of the seismic energy $E_{s}$ with the potential energy $E_{p}$ (Figure 7a) shows that only a very 
small amount of the fall energy is transmitted as seismic waves. The $E_{s} / E_{p}$ ratio varies between $10^{-6}$ and $10^{-3}$ (see Table 1 ). These results agree with the energy conversion values (also between $10^{-6}$ and $10^{-3}$ ) found by Weichert et al. (1994) from $M_{S}$ values for rockslides. They highlight the strong influence of nonlinear effects during the impact. In particular, the highly variable geotechnical site conditions of the impact zone (from soil to rock) probably explain the large variation of $E_{s} / E_{p}$ ratios and the poor correlation between $M_{r f}$ (or $E_{s}$ ) and the rock-fall characteristics $H_{f}, V$ and $D_{p}$ (correlation coefficient $R$ lower than 0.5 , Figure $7 \mathrm{~b}, \mathrm{c}, \mathrm{d})$. All the events where the rocks fell on a marly slope $(R l$, $R 5$ to $R 9$ ) exhibit $M_{r f}$ values below the regression line, resulting from the low coefficient of restitution of the slope surface. Two data points $(R 3$ and $R 5)$ are systematically far from the best regression line. $R 5$ is the first rock-fall in a sequence of 5 events that occurred in the same place and shows an unexpected low magnitude value, compared to the other events. It occurred in winter and the mass failed on a snow layer which could have absorbed a part of the energy, particularly on such a steep slope $\left(65^{\circ}\right)$. Event $R 3$ exhibits a relatively high magnitude for the values of fall height and runout (Fig. $7 \mathrm{~b}$ and $7 \mathrm{c}$ ). In Figure $7 \mathrm{~b}$, the vertical distance to the line could result from the initial sliding phase which contributed to the seismic energy and was not considered in the height-fall estimation. No explanation was found for the magnitude-runout graph which shows a very poor correlation. On the contrary, the signal duration $t_{30}$ exhibits a better correlation with the potential energy $(\mathrm{R}=0.69$, Figure $7 \mathrm{e})$, with the runout $(\mathrm{R}=0.61$, Figure $7 \mathrm{~h})$ and to a lesser extent with the volume $(\mathrm{R}=0.47$, Figure $7 \mathrm{~g})$. No correlation was found between the fall height $H_{f}$ and the ground-motion duration $t_{30}$ (Figure 7f). Although limited in number, these results show that, contrary to earthquakes, the seismic energy derived from records can not characterize rock-falls. Alternatively, the signal duration $t_{30}$ is more promising. The good correlation between $t_{30}$ and $D_{p}$ indicates that the signal duration, which conveys information on the different phases of the failure process, is controlled by the propagation phase of the rock-fall. As the runout distance increases with the rock-fall volume $V$ (Legros, 2002), correlations are also found between $\mathrm{t}_{30}$ and the rock-fall characteristics $E_{p}$ and $V$. However, the limited number of events considered in this study does not allow us to propose quantitative relationships between these parameters, and these preliminary results should be validated in the future for a larger number of events. Due to the limited success of global seismic parameters for characterizing rock-falls, we 
attempt to understand the different phases within the seismograms, using signal processing and 2D numerical modeling.

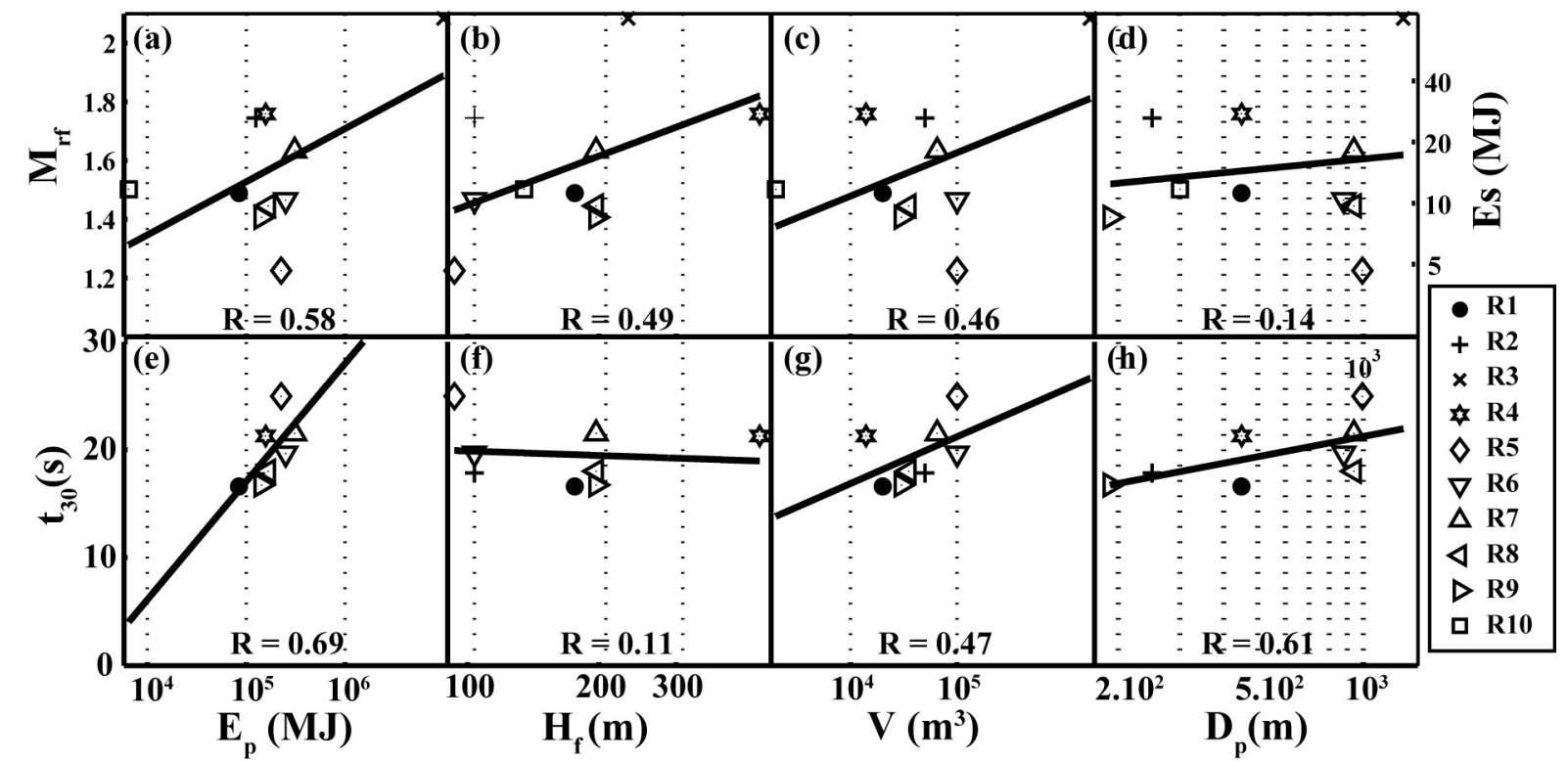

Figure 7. Comparison between ground-motion characteristics (rock-fall seismic magnitude $M_{r}$,

seismic energy $E_{s}$ and duration $t_{30}$ ) and rock-fall parameters (potential energy $E_{p}$, fall height $H_{f}$, volume $V$, runout $D_{p}$,). $\mathrm{R}$ is the correlation coefficient of the linear regression analysis (solid black lines).

\section{Spectrogram and polarization analysis}

Rock-falls seismograms (Figure 4) exhibit complex shapes with an irregular envelope and several energy pulses, probably resulting from the existence of multiple sources and from the propagation of different waves. During an event (Figure 1), seismic waves are likely to be generated during the initial slide and/or detachment of the block (elastic rebound), the impact on the ground and the mass propagation. As these seismic sources are all superficial, the energy is radiated as both body and surface waves. In the following we attempt to identify distinct seismic phases in the seismograms. Figure 8 shows the signals and the corresponding spectrograms for three events $(R 1, R 5$ and $R 9)$ recorded at two close stations. The spectrograms are calculated with a sliding window of 2 seconds and an overlap of $80 \%$.

For the smallest event $R 1\left(\mathrm{~V}=210^{4} \mathrm{~m}^{3}\right)$, the seismogram recorded at station OG13 (Figure 8a), along with the spectrogram (Figure 8b), clearly shows four distinct seismic phases: the first $P$-wave at 
3 seconds, a lower-frequency wave (around $2 \mathrm{~Hz}$ ) arriving about 3 seconds later, a high-frequency wave (from 3 to $10 \mathrm{~Hz}$ ) at 9 seconds and a second low-frequency energetic wave $(2 \mathrm{~Hz}) 3$ seconds later, just before the signal slowly begins to decrease. The time difference (6 seconds) between the first onset and the second high-frequency wave is compared to the theoretical fall duration $D_{f}$ given by the equation:

$$
D_{f}=t_{i}-t_{d}=\sqrt{\frac{2 \times H_{f}}{g}}
$$

where $t_{i}$ is the impact time, $t_{d}$ is the time of the mass detachment, $H_{f}$ is the fall height $(170 \mathrm{~m}$ for $R l)$ and $g$ is the gravity constant $\left(9.81 \mathrm{~m} / \mathrm{s}^{2}\right)$. The computed fall duration $(6.2 \mathrm{~s}$ for R1, see Table 3 and solid line in Figure 8) is consistent with the observed time difference, supporting the existence of at least two seismic sources: one corresponding to the initial rupture associated with an elastic rebound during the detachment, and the other generated at the rock impact on the slope. In Figure 8a are drawn two solid vertical lines showing the first onset time $t_{d}$ and the impact time $t_{i}$. The signal associated with the impact has higher amplitude and higher frequency, compared to the one observed during the elastic rebound phase (Figure $8 \mathrm{~b}$ ). In the same figure are also shown with vertical dashed lines the theoretical times $t_{d S}$ and $t_{i S}$ of the surface waves generated during the mass detachment and impact, estimated from the seismic model used for earthquake location (Paul et al, 2001).

\begin{tabular}{|c|c|c|c|c|c|c|c|c|}
\hline Event & \begin{tabular}{|c} 
Drop \\
Height \\
(m)
\end{tabular} & Station & \begin{tabular}{|c} 
Fall \\
duration \\
$D_{f}(\mathbf{s})$ \\
\end{tabular} & $\begin{array}{l}\text { Distance } \\
(\mathbf{k m})\end{array}$ & $t_{d}(\mathbf{s})$ & $t_{i}(\mathrm{~s})$ & $\begin{array}{l}t_{d s} \\
(\mathbf{s})\end{array}$ & $t_{i S}(\mathrm{~s})$ \\
\hline \multirow{2}{*}{ R1 } & \multirow{2}{*}{190} & OG13 & \multirow{2}{*}{6.2} & 23.9 & 3.3 & 9.5 & 6.2 & 12.4 \\
\hline & & OG17 & & 40.2 & \begin{tabular}{|l|}
6.9 \\
\end{tabular} & \begin{tabular}{|l|}
13.1 \\
\end{tabular} & 11.8 & 18,0 \\
\hline \multirow{2}{*}{ R5 } & \multirow{2}{*}{90} & OG17 & \multirow{2}{*}{4.3} & 25,0 & 3.6 & \begin{tabular}{|l|}
7.8 \\
\end{tabular} & 6.6 & 10.9 \\
\hline & & OG14 & & 27.3 & 4.2 & 8.4 & 7.5 & 11.8 \\
\hline \multirow{2}{*}{$\mathbf{R}$} & \multirow{2}{*}{190} & OG17 & \multirow{2}{*}{6.2} & 25,0 & 3.9 & 10.1 & 6.9 & 13.1 \\
\hline & & OG14 & & 27.3 & 4.3 & 10.5 & 7.6 & \begin{tabular}{|l|}
13.9 \\
\end{tabular} \\
\hline
\end{tabular}

Table 3. Arrival times of $\mathrm{P}$ and surface waves for the three rock-falls R1, R5 and R9. $t_{d}$ : arrival time of the $P$-wave due to the block detachment, as measured on the seismograms; $t_{i}$ : theoretical impact time obtained by adding the fall duration to $t_{d \cdot} ; t_{d S}$ and $t_{i S}$ are the computed surface wave arrival times for the detachment and the impact, respectively. 
Computed times are given in Table 3, along with fall-height values and epicentral distances. The fit between these theoretical times and the two observed low-frequency wave arrivals is excellent, supporting the interpretation that the four main seismic phases observed in the seismogram are due to the generation of $\mathrm{P}$ and surface waves during the detachment and the impact of the mass.

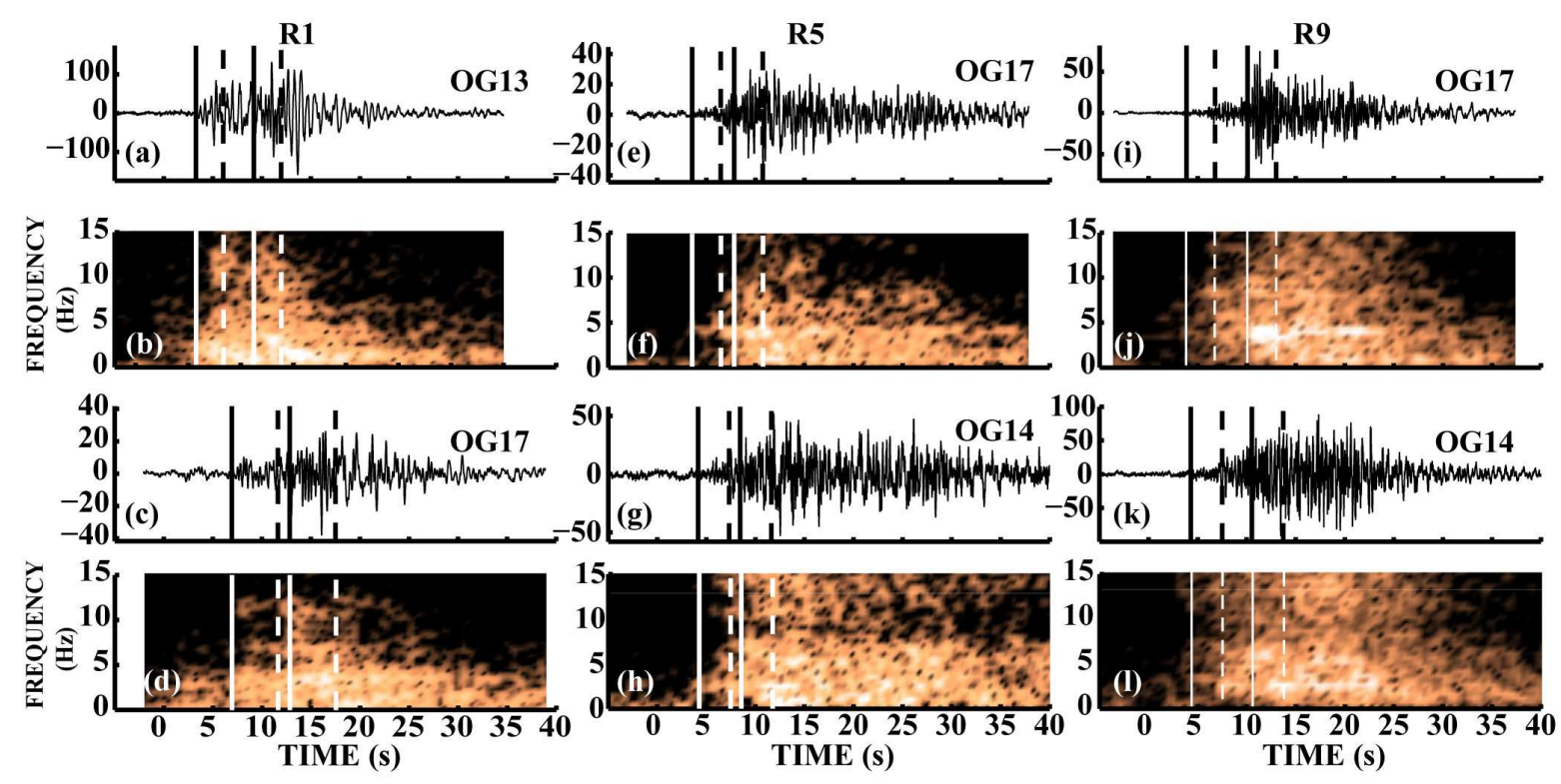

Figure 8. Vertical- component signals (top) and corresponding spectrograms (bottom) for the $R l$ (a to d), $R 5$ (e to h) and $R 9$ (i to l) events recorded at two different stations. The first solid line shows the $P$ wave generated during the initial rupture $\left(t_{d}\right)$ while the second indicates the theoretical impact time after the fall $\left(t_{i}\right)$ computed with formula 7. Dashed lines show the surface-wave arrival times for the two sources ( $t_{d S}$ and $t_{i s}$ for the first and second source, respectively).

A similar analysis was made on the other 5 couples of seismograms and spectrograms and the four theoretical times are indicated in the same way in Figures $8 \mathrm{c}$ to 81 . These times are usually associated with energy pulses exhibiting frequency variations consistent with the impact (high frequency) or with the arrival of surface waves (low frequency). However, the seismograms are globally more complex. On the one hand, some features can be obscured by the superposition of two seismic phases, depending on the relation between the fall duration and the difference between the propagation times of $\mathrm{P}$ and surface waves. This is observed for the second record (station OG17, Figure 8c) of event $R l$, 
where $P$-waves generated by the impact interfere with surface waves radiated during the detachment. On the other hand, the source mechanism for the two other greater rock-falls $R 5$ and $R 9$ is clearly more complex than the one proposed for $R l$, as shown by the presence of energy pulses later in the signal (Figures 8e, 8g, 8i, 8k). In particular, the seismograms and spectrograms for rock-fall $R 5$ $\left(V=110^{5} \mathrm{~m}^{3}\right)$ suggest a multi-fall sequence and/or the generation of waves during the mass propagation. However, the time shift between the source detachment and the impact is consistent with the theoretical free-fall duration. As stated before, the late slowly decreasing-amplitude part of the signal is controlled by the propagation phase, as shown by the relation between the signal duration and the runout distance.

In order to validate the interpretation of $P$-waves and surface waves, wave polarization analyses were carried out on the available 3-component stations. Figures 9 and 10 show the seismograms recorded at station OG14 and the particle motions for the rock-falls $R 5$ and $R 9$, respectively. The polarization analysis was performed on short time windows ( 0.5 to 1.5 seconds, according to the wave period) at the arrival times $\left(t_{d}, t_{i}, \mathrm{t}_{d s}\right.$ and $\left.t_{i S}\right)$ of the four identified waves. At $t_{d}$ and $t_{i}$ times (Figures $9 \mathrm{~b}$, 9d, 10b and 10d), the particle motions have the characteristics of a $P$-wave, mainly vibrating along a particular direction in the radial vertical plane, with an incidence angle between $45^{\circ}$ and $60^{\circ}$. At $t_{d s}$ and $t_{i S}$ times (Figures 9c, 9e, 10c and 10e), the particle motions clearly exhibit an elliptical polarization typical of surface waves, with however a difference in the polarization direction. For both rock-falls, surface waves generated during the detachment (Figures 9c and 10c) are Rayleigh-type waves polarized in the propagation plane, consistently with the approximation of the elastic rebound by a vertical force. On the contrary, the surface waves radiated at the time of the impact also include Lovetype waves with a significant tangential component (Figures 9e and 10e), particularly for event $R 9$. Both rock-falls moved in a direction perpendicular to the line linking the events to the station OG14 (Figure 2). As the slope at the impact area is greater than $50^{\circ}$ for the two events, a near vertical impact then induces a strong parallel-to-the-surface shear force, which generates Love-type surface waves at station OG14. Additional Love-type waves are also observed in the later part of the signals (not shown) and could result from the shearing due to the sliding mass if the movement evolves to a rock 
avalanche. Unfortunately, no three-component station was located in the propagation plane to show the generation of Rayleigh waves in this plane during the impact.
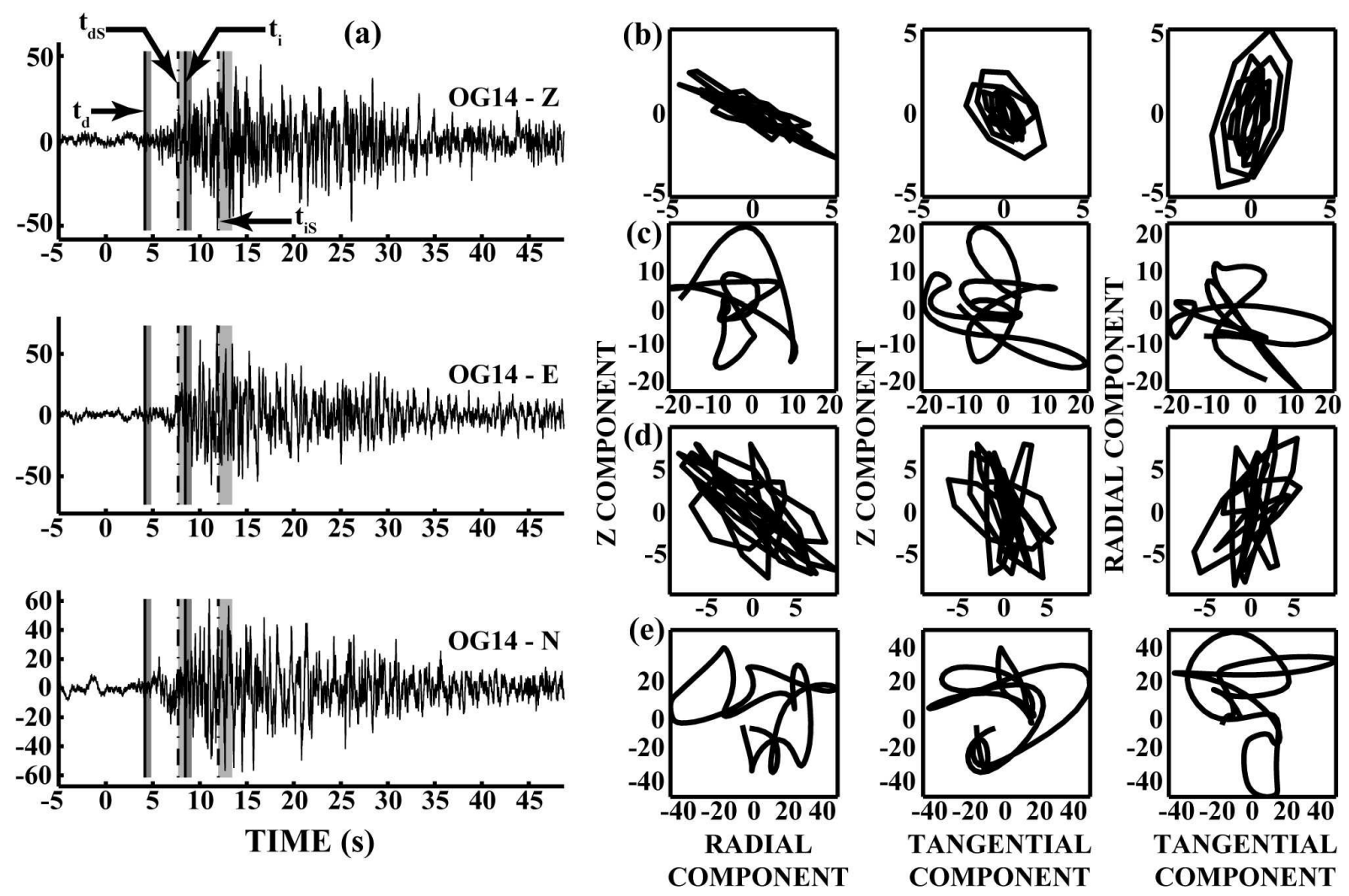

Figure 9. Polarization analysis of signals recorded at station OG14 for the $R 5$ event. (a) 3-component seismograms with the four arrival times $t_{d}, t_{i}, t_{d S}$ and $t_{i S}$ (vertical solid and dot-dashed lines). (b) and (c) Particle motions of the $P$-waves (during $0.5 \mathrm{sec}$ ) and surface waves (during $1.5 \mathrm{sec}$ ) at times $t_{d}$ and $t_{d s}$ (detachment phase) in the three polarization planes. (d) and (e) Idem for times $t_{i}$ and $t_{i S}$ (impact phase).

In conclusion, polarization analysis on 3-component stations confirms the types of waves detected in the seismogram and spectrogram study, showing the existence of at least two seismic sources in the rock-fall records. The first, which is probably due to the rupture and detachment phases, generates non-impulsive $P$-waves, while the second, which is interpreted as resulting from the impact, generates higher frequency and more energetic waves. The seismic characteristics of these two phenomena are studied using 2D numerical simulations. 

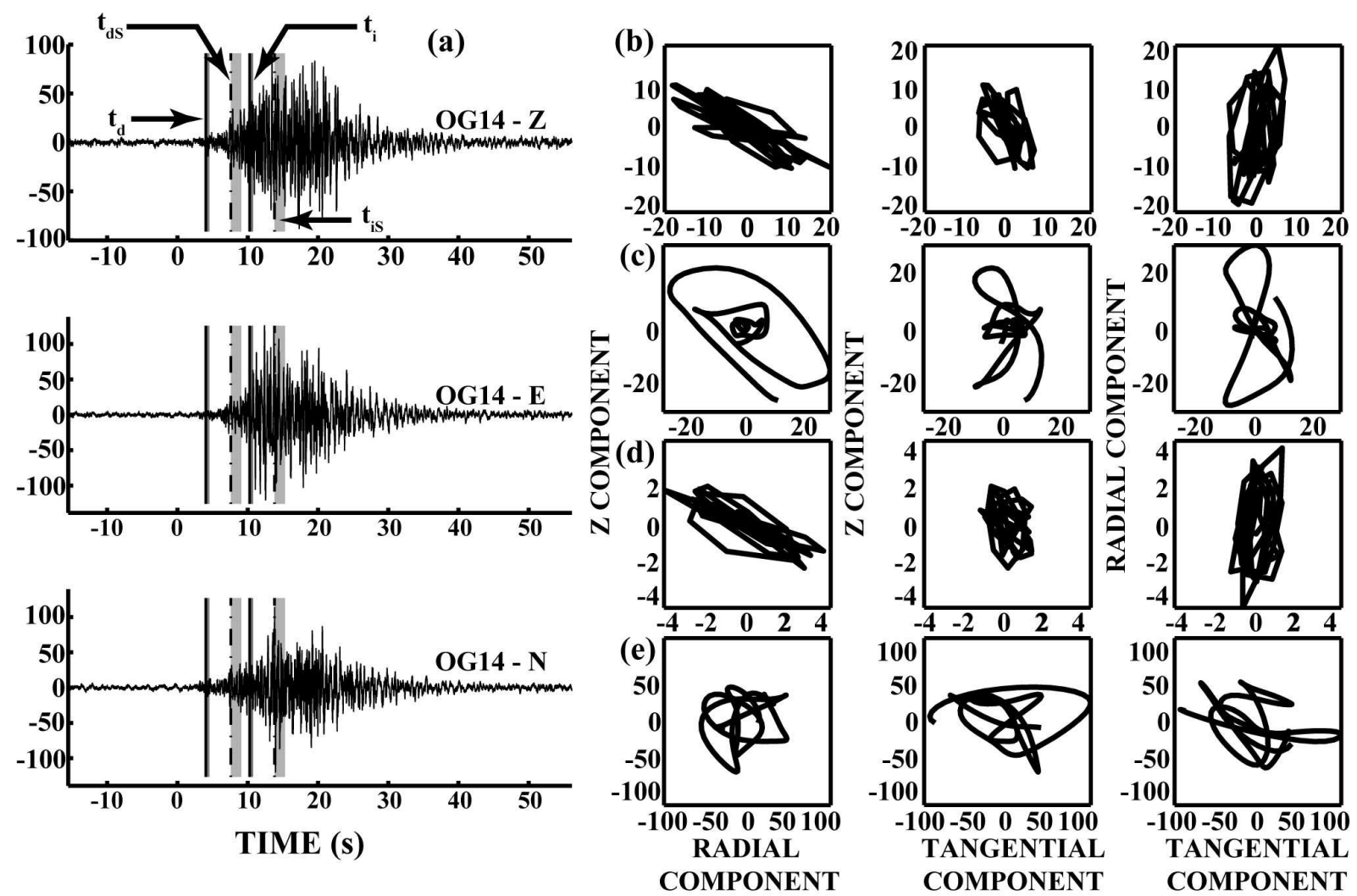

Figure 10. Polarization analysis of the signals recorded at station OG14 for the $R 9$ event. Same caption as in Figure 9.

\section{Numerical Modeling}

We simulate the fall of a rectangular block detaching from a cliff along a vertical plane (Figure 11a). The size of the block is $40 \times 80 \mathrm{~m}$ and the fall height is $170 \mathrm{~m}$. The explicit 2D dynamic finiteelement code Plast2 (Baillet et al., 2005; Baillet and Sassi, 2006) is used to simulate detachment, frictional contact, fall and impact. The motion equation is both spatially and temporally discretized by using the finite-element method and the $\beta_{2}$ explicit time integration scheme (Carpenter et al., 1991), respectively. In order to ensure stability, the explicit scheme satisfies the usual Courant-FriedrichsLevy (CFL) condition ( $\Delta t \leq \xi(h / c)_{\min }$ ) where $\Delta t$ is the time step, $h$ is the element size, $c$ is the wave speed, and $\xi$ is a positive constant $(\xi<1, \xi \approx 0.5$ in most practical purposes). Correct wave propagation is obtained by using 10 finite elements per wavelength (Mullen and Belytschko, 1982) with the absorbing boundary conditions proposed by Stacey (1988). Computations were made with 89,000 quadrilateral finite elements with an element size of $5 \mathrm{~m}$. 
The code Plast 2 considers large strains, large displacements and large rotations, as well as non linear material behavior. Contact non-linearity (block/cliff interface) is taken into account by using the forward increment Lagrange multiplier method (Carpenter et al., 1991) which enables the evaluation of the normal and tangential contact stresses, as well as the determination of whether the contact surfaces locally stick, slip, or separate. The contact algorithm uses slave nodes on the block and target surfaces on the cliff. An elementary target surface defined by two nodes is broken down into Ferguson patch with a $C^{1}$ continuity across the adjacent boundary (Faux and Pratt, 1979). A model coupling unilateral contact condition, Coulomb friction (constant coefficient) and adhesion (Raous et al., 1999) is used for computing the contact stresses and displacements at each iteration. The intensity of adhesion is characterized by an internal variable $\beta$ with $\beta=1$ for total adhesive interface, and $\beta=0$ for contact without adhesion.

First, the seismic signals generated during the block detachment are computed at two points $A$ and $B$ located at about $375 \mathrm{~m}$ from the cliff (Figure 11a), on the lower and upper surfaces. The block and the cliff are supposed to be elastic ( $P$-wave velocity $V_{p}=5820 \mathrm{~m} / \mathrm{s} ; S$-wave velocity $V_{s}=3112 \mathrm{~m} / \mathrm{s}$; density $\rho=2.7$ ). Thus, the impact of the detached stiff elastic block is simulated for three rheological conditions of the ground, which are given in Table 4. In the first case, the ground is elastic with the same characteristics as the block. In the second case, the ground is still elastic but softer $\left(V_{p}=\right.$ $\left.1700 \mathrm{~m} / \mathrm{s}, V_{s}=909 \mathrm{~m} / \mathrm{s}, \rho=1.5\right)$ in order to simulate the impact conditions of a limestone block on a marl layer or on scree deposits. In the third case, we use an elasto-plastic law for simulating the non linear behavior of the ground. For the marl characteristics, the values given by Eberhardt et al. (2005) have been taken $\left(c=65 \mathrm{KPa}\right.$ and $\Phi=35^{\circ}$ ). Here, we chose to use Von Mises criterion, with a corresponding elastic limit in compression of $288 \mathrm{KPa}$. 


\begin{tabular}{|c|c|c|c|}
\hline \multirow{2}{*}{$\begin{array}{c}\text { Case } \\
\#\end{array}$} & $\begin{array}{c}\text { Block and cliff } \\
\text { characteristics }\end{array}$ & \multicolumn{2}{|c|}{ Ground properties } \\
\cline { 2 - 4 } & Elastic & Elastic & Plastic \\
\hline \multirow{2}{*}{1} & $\mathrm{Vp}=5820 \mathrm{~m} / \mathrm{s}$ & $\mathrm{Vp}=5820 \mathrm{~m} / \mathrm{s}$ & - \\
& $\mathrm{Vs}=3112 \mathrm{~m} / \mathrm{s}$ & $\mathrm{Vs}=3112 \mathrm{~m} / \mathrm{s}$ & \\
& $\rho=2.7$ & $\rho=2.7$ & \\
\hline \multirow{2}{*}{2} & $\mathrm{Vp}=5820 \mathrm{~m} / \mathrm{s}$ & $\mathrm{Vp}=1700 \mathrm{~m} / \mathrm{s}$ & \\
& $\mathrm{Vs}=3112 \mathrm{~m} / \mathrm{s}$ & $\mathrm{Vs}=909 \mathrm{~m} / \mathrm{s}$ & \\
& $\rho=2.7$ & $\rho=1.5$ & \\
\hline \multirow{3}{*}{3} & $\mathrm{Vp}=5820 \mathrm{~m} / \mathrm{s}$ & $\mathrm{Vp}=1700 \mathrm{~m} / \mathrm{s}$ & $\sigma_{\mathrm{y}}=348 .\left(2.10^{-3}+\varepsilon^{\mathrm{p}}\right)^{0.03}$ \\
& $\mathrm{Vs}=3112 \mathrm{~m} / \mathrm{s}$ & $\mathrm{Vs}=909 \mathrm{~m} / \mathrm{s}$ & $\sigma_{\mathrm{y}\left(\varepsilon^{\mathrm{p}}=0\right)}=289 \mathrm{KPa}$ \\
& $\rho=2.7$ & $\rho=1.5$ & \\
\hline
\end{tabular}

Table 4: Dynamic characteristics of the block and the ground in the three simulation cases. $V_{p}$ and $V_{s}$ are the $P$-wave and $S$-wave velocities, $\rho$ is the density, $\sigma_{y}$ is the yield strength (Von Mises criterion) and $\varepsilon^{p}$ is the equivalent plastic strain.

The seismic signals generated during the detachment at the two points $A$ and $B$ in the $0-20 \mathrm{~Hz}$ frequency range are shown in Figures $11 \mathrm{~b}$ and $11 \mathrm{c}$, respectively. They both exhibit a sharp signal, with a greater amplitude at point $B$ (upper surface) than at point $A$ (lower surface). This difference, which results from the difference of distance due to the cliff height and from the scattering on the edges, should attenuate at large distance when the cliff height becomes negligible. In the following we will consider the signal on the lower surface (point $A$ ) for comparing it to the seismograms due to the impact. The signals generated by the detachment of two blocks with different sizes ( $20 \mathrm{x} 40 \mathrm{~m}$ and 40 $\mathrm{x} 80 \mathrm{~m}$ ) are shown in Figures 11d and 11e, respectively, as well as the corresponding spectrograms (Figures $11 \mathrm{i}$ and $\mathrm{j}$ ). For the $40 \mathrm{x} 80 \mathrm{~m}$ block, the signal and the spectrogram show a maximum energy at very low frequency (below $2 \mathrm{~Hz}$ ) with a permanent displacement due to the elastic rebound of the cliff after the block detachment $(\mathrm{t}>0.2$ seconds). For the $20 \mathrm{x} 40 \mathrm{~m}$ block, this effect is less visible and the maximum energy is shifted to a higher frequency in relation with the size of the block. The signals generated by the impact at point A for the three rheological conditions of the ground (table 4) are plotted in Figures 11f, 11g and 11h, along with the corresponding spectrograms (Figures 11k, 111 and $11 \mathrm{~m})$. The difference of time between the detachment and the impact events corresponds to the fall duration (about 5.8s). 

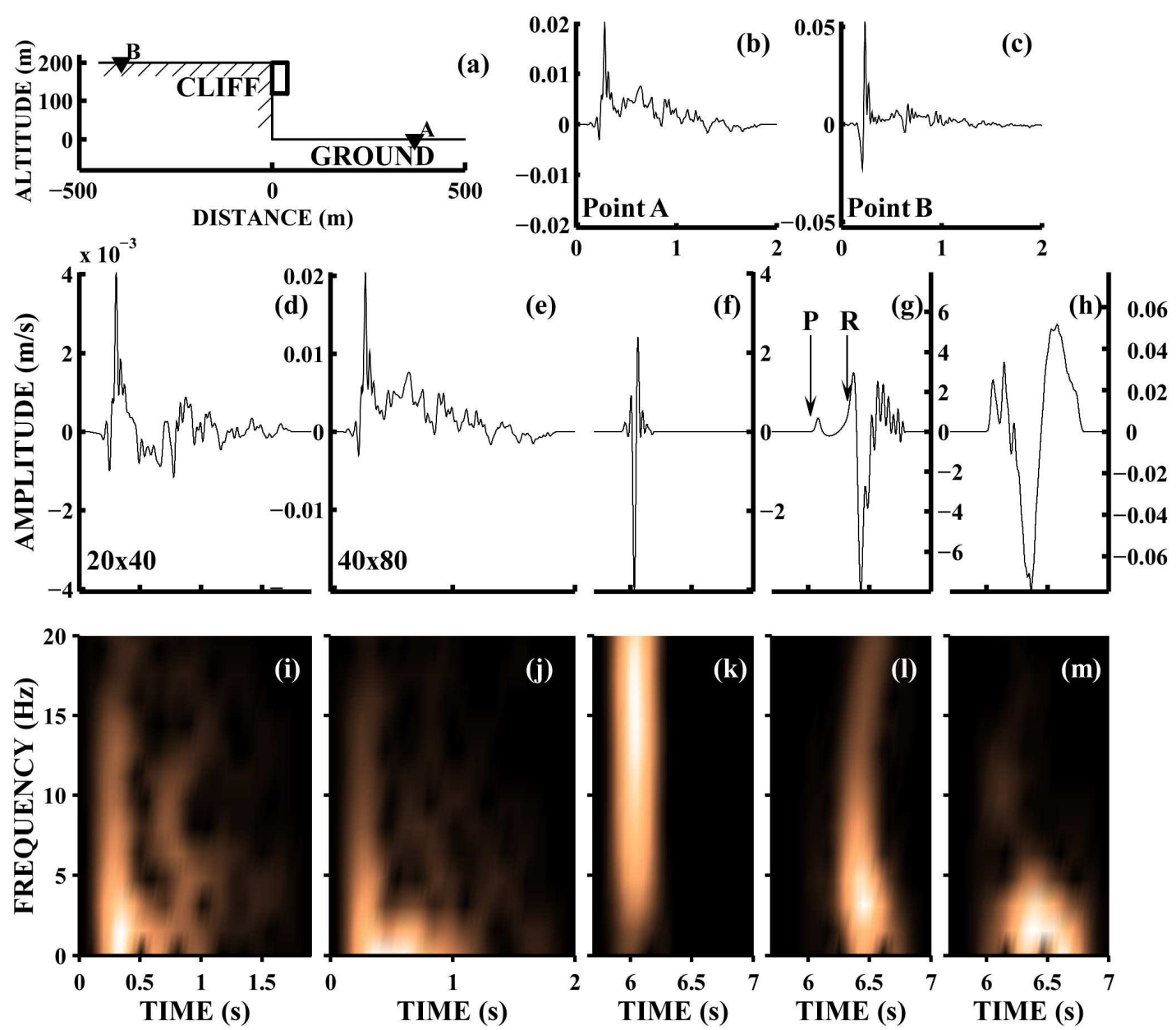

Figure 11. Numerical simulations of the detachment and impact of a block. (a) Geometry of the model with the overhang block. (b) and (c) synthetic seismograms computed at points $A$ and $B$, respectively, during the detachment of the $40 \times 80 \mathrm{~m}$ block. (d) and (i) seismogram and spectrogram computed during the detachment of the $20 \times 40 \mathrm{~m}$ block at point $A$. (e) and (j), seismogram and spectrogram computed during the detachment of the $40 \times 80 \mathrm{~m}$ block at point $A$. (f) to (h) seismograms simulated for the impact of the $40 \times 80 \mathrm{~m}$ block on an elastic rigid ground, on an elastic soft ground and on a elasto-plastic ground (cases 1 to 3 of table 4), $P: P$-waves, $R$ : Rayleigh waves. (k) to (m) corresponding spectrograms.

In the two elastic cases (Figure 11f and 11g), the waves generated during the impact are 200 to 350 times greater than those radiated during the detachment (these figures have to be divided by two if we consider point $B$ for the detachment). $P$-wave is better distinguished from Rayleigh wave for the soft elastic medium (case 2) due to the lower propagation velocities. In the spectrograms, the signal on the elastic stiff ground (Figure 11f) exhibits Dirac-like characteristics with energy spread over the whole 
frequency range (Figure 11k), while in the soft elastic case, the energy is more concentrated between 1 and $10 \mathrm{~Hz}$ (Figure 111). Although the synthetic signals are simulated at small distance from the source, these results agree with the observations made on the real seismograms, that the signal associated to the impact has higher amplitude and a higher frequency, compared to the one observed during the detachment phase. However, the real amplitude difference is not as high as the one simulated and a ground plastic behavior is tested in order to evaluate the nonlinear effect on the wave characteristics (Figures $11 \mathrm{~h}$ and $11 \mathrm{~m})$.

The introduction of plasticity in the ground with soft elastic characteristics dramatically decreases the impact amplitude by a factor 100 and strongly affects the spectral energy which concentrates below $5 \mathrm{~Hz}$. The signal generated during the impact still exhibits greater amplitude ( 2 to 3.5 ) than the one due to the detachment, with a lower ratio range. This ratio is comparable to the one observed on measured seismograms (compare Figures 8 and 11). Even with a simple plastic law, these numerical results explain some of the main characteristics of observed seismograms and highlight the strong influence of ground non-linear behavior on the waves generated during the impact. The consequence is that frequency content and amplitude of the impact-related part of the signal cannot be used for extracting information on the fallen block or on the rupture mechanism. That analysis has to be focused on the early part of the seismograms, linked to the detachment phase, which shows spectral variations with the block size at low frequency.

\section{Conclusions}

We analyzed seismograms recorded during rock-falls in the western Alps by the French permanent seismological network Sismalp with the aim of getting new information on the rock-fall mechanism. We used records of ten known events which occurred between 1992 and 2001. The study of the peak ground motions showed that the regional attenuation relation used for earthquakes is inappropriate for rock-falls. A new empirical attenuation relation for rock-fall-induced motions was derived from the data set, allowing a rock-fall seismic magnitude to be attributed to each event. In agreement with previous works, the comparison between the seismic energy and the potential energy released during rock-falls showed that only a very small amount (between $10^{-6}$ and $10^{-3}$ ) of the fall energy is 
transmitted as seismic waves. It highlights the effect of nonlinear processes (friction, cracking, plastic deformation) which probably explain the very poor correlation found between the seismic magnitude $M_{r f}$ (or Es) and the rock-fall characteristics $H_{f}, V$ and $D_{p}$. These results imply that, contrary to earthquakes, the peak ground amplitude, dominated by the impact source, is not a good parameter for characterizing rock-falls. On the other hand, we showed that the signal duration was correlated to the runout distance, thus confirming the role played by the propagation phase on this characteristic of the seismogram. As the Sismalp network is equipped with short-period seismometers, it can only be concluded that the corner frequency $f_{0}$ is close to or below $1 \mathrm{~Hz}$ for the investigated rock-falls. Another step forward for a more detailed study of the rock-fall dynamic mechanism would be to remove the propagation effects from the seismic records, using blind deconvolution methods (Liao and Huang, 2005, Sèbe et al, 2005).

Signal and particle-motion analyses pointed out the complexity of the seismograms, with the arrival of at least two $P$-wave trains and two surface-wave trains. We linked these seismic phases to two distinct sources: the rupture and detachment of the block from the cliff generating an elastic rebound on the one hand, and the waves radiated during the impact following the fall on the other hand. The fall phenomenon might include other complex processes (fragmentation of the falling mass, interaction with the topography during the fall). However, preliminary 2D elastic and plastic numerical results retrieved the major spectral and amplitude characteristics of the rock-fall records. In particular, they highlighted the major effect of the plastic deformation on waves generated during the impact. Our numerical results also showed an influence of the block volume on the low-frequency content of the waves, suggesting that the first $P$-wave train could be used for characterizing rock-falls if high-quality broad-band seismometer records were available.

\section{Acknowledgements}

We thank S. G. Evans and an anonymous reviewer who provided helpful comments that improved the manuscript. 


\section{References}

Ambraseys, N.N., K.A. Simpson and J.J. Bommer (1996). Prediction of horizontal response spectra in Europe. Earthq. Eng. Struct. Dyn. 25, 371-400.

Baillet, L., V. Linck, S. D'Errico, B. Laulagnet and Y. Berthier (2005). Finite element simulation of dynamic instabilities in frictional sliding contact. Journal of Tribology-Transactions of the Asme 127, 652-657.

Baillet L. and T. Sassi (2006). Mixed finite element methods for the Signorini problem with friction. Numerical Methods for Partial Differential Equations 22, Issue 6, 1489-1508.

Berge-Thierry, C., F. Cotton, O. Scotti, D.A. Griot-Pommera and Y. Fukushima (2003). New empirical response spectral attenuation laws for moderate European earthquakes. Journal of Earthquake Engineering 7, 193-222.

Berrocal, J., A.F. Espinosa and J. Galdos (1978). Seismological and Geological Aspects of Mantaro Landslide in Peru. Nature 275, 533-536.

Brodsky, E.E., E. Gordeev and H. Kanamori (2003). Landslide basal friction as measured by seismic waves. Geophysical Research Letters 30, 2236.

Carpenter N.J., R.L. Taylor and M.G. Katona (1991). Lagrange constraints for transient finite element surface contact. International Journal for Numerical Methods in Engineering 32, 130-128.

Corominas, J. (1996). The angle of reach as a mobility index for small and large landslide. Canadian Geotechnical Journal 33, 260-271.

Cruden, D.M. and D.J. Varnes (1996). Landslide types and processes. In: Turner, A.K., Schuster, R.L. (Eds), Landslides : Investigation and Mitigation. Transportation Research Board, National Academy Press Washington, Special Report 247, DC, 36-75.

Dahlen, F.A. (1993). Single-force representation of shallow landslide sources. Bull. Seism. Soc. Am. $83,130-143$.

Eberhardt, E., K. Thuro and M. Luginbuehl (2005). Slope instability mechanism in dipping interbedded conglomerates and weathered marns-the 1999 Rufi landslide, Switzerland. Engineering Geology 77, 35-56 
Eissler, H.K. and H. Kanamori (1987). A Single Force Model for the 1975 Kalapana, Hawaii, Earthquake. Journal of Geophysical Research 92 , 4827-4836.

Evans, S.G. and O. Hungr (1993). The assessment of rockfall hazard at the base of talus slopes: Canadian Geotechnical Journal, 30, p. 620-636.

Faux, I.D. and M.J. Pratt (1979).Computational geometry for design and manufacture. Mathematics and application, Elli Horwood Publishers, 360p

Frayssines, M. and D. Hantz (2006) Failure mechanisms and triggering factors in calcareous cliffs of the Subalpine Ranges (French Alps). Engineering Geology 86, 256-270.

Gasperini, P. (2002), Local magnitude revaluation for recent Italian earthquakes (1981-1996). Journal of Seismology, 6, 503-524.

Giani, G.P. (1992), Rock slope stability analysis. Balkema, Rotterdam, 362p.

Hasegawa, H.S. and H. Kanamori (1987). Source Mechanism of the Magnitude-7.2 Grand-Banks Earthquake of November 1929 - Double Couple or Submarine Landslide. Bull. Seism. Soc. Am. 77(6), 1984-2004.

Hsü, K.J. (1975) Catastrophic debris streams (sturzstroms) generated. by rockfalls. Geol Soc Am Bull 86: $129-140$.

Hungr, O., S.G. Evans., M.J. Bovis and J.N. Hutchinson (2001). A review of the classification of landslides of the flow type, Environmental \& Engineering Geoscience, 7, 221-238.

Kanamori, H. (1977). The energy release in great earthquake. Journal of Geophysical Research 82, 2981-2987.

Kanamori, H. and J.W. Given (1982). Analysis of Long-Period Seismic-Waves Excited by the May 18, (1980), Eruption of Mount St Helens - a Terrestrial Monopole. Journal of Geophysical Research 87, 5422-5432.

Kanamori, H., J.W. Given and T. Lay (1984). Analysis of Seismic Body Waves Excited by the Mount St-Helens Eruption of May 18, 1980. Journal of Geophysical Research 89, 1856-1866.

Keusen H. R., (1998). Die Bergstürze auf der Sandalp 1996 Risikobeurteilung und Gefahrenmanagement, Bull. Angew. Geol., 3, 89-102. 
Kradolfer, U. and D. Mayer-Rosa (1988). Attenuation of seismic waves in Switzerland. In: Recent Seismological Investigations in Europe, Proc. 19th Gen. Ass. Europ. Seism. Comm., Nauka, Moscow, 481-488.

La Rocca, M., D. Galluzzo, G. Saccorotti, S. Tinti, G.B Cimini. and E. Del Pezzo (2004). Seismic Signals Associated with Landslides and with a Tsunami at Stromboli Volcano, Italy. Bull. Seism. Soc. Am., 94, 1850-1867.

Legros, F. (2002). The mobility of long-runout landslides. Engineering Geology, 63, 301-331.

Liao, B-Y and H-C Huang (2005). Estimation of the Source Time Function Based on Blind Deconvolution with Gaussian Mixtures. Pure and Applied geophysics 162, 479-494

McSaveney, M.J. (2002). Recent rock-falls and rock avalanches in Mount Cook National Park, New Zealand. p. 35-70 In: Evans SG, DeGraff JV eds. Catastrophic landslides: effects, occurrence and mechanisms. Geological Society of America Reviews in Engineering Geology 15.

Mills, H.H. (1991). Temporal Variation of Mass-Wasting Activity in Mount St-Helens Crater, Washington, USA - Indicated by Seismic Activity. Arctic and Alpine Research 23(4), 417-423.

Mullen, R. and T. Belytschko (1982). Dispersion analysis of finite element semi discretizations of the two dimensional wave equation. Int. J. Num. Methods. Eng. 18, 11-29.

Myers, S, D. Rock and K. Mayeda (2000). Feasibility of Monitoring Rock Fall in Yosemite Valley Using Seismic Methods, Open file technical report, 17 p.

Nicoletti, P.G. and M. Sorriso-Valvo (1991). Geomorphic controls of the shape and mobility of rock avalanches. Geological Society of America Bulletin 103, 1365-1373.

Norris, R.D. (1994). Seismicity of rock-falls and avalanches at three cascade range volcanoes: Implications for seismic detection of hazardous mass movements. Bull. Seism. Soc. Am. 84, 1925-1939.

Okura, Y., H. Kitahara, T. Sammori and A. Kawanami (2000). The effect of rock-fall volume on runout distance. Engineering Geology, 58, 109-124.

Paul, A., M. Cattaneo, F. Thouvenot, D. Spallarossa, N. Bethoux and J. Fréchet (2001). A threedimensional crustal velocity model of the south-western Alps from local earthquake tomography. Journal of Geophysical Research 106, 19,367-19,390 
Raous, M., L. Cangemi and M. Cocu (1999). A consistent model coupling adhesion, friction and unilateral contact. Computer Methods in Applied Mechanics and Engineering 177, ${ }^{\circ} 3-4,383-$ 399.

Ravanel, L. and P. Deline (2006). Nouvelles methodes d'étude de l'évolution des parois rocheuses de haute montagne: application au cas des Drus. Proceedings of the workshop «Géologie et Risques Naturels : la gestion des risques au Pays du Mont Blanc», November 16, 2006, Sallanches, 48-53.

Richter, C.F. (1935). An instrumental earthquake magnitude scale. Bull. Seism. Soc. Am. 25, 1-32.

Richter, C.F. (1958). Elementary Seismology. San Francisco 768 pp.

Sèbe, O., P-Y. Bard and J. Guilbert (2005). Single station estimation of seismic source time function from coda waves: the Kursk disaster. Geophysical Research Letters 32, L14308

Stacey, R. (1988). Improved transparent boundary formulations for the elastic-wave equation. Short Note. Bull. Seism. Soc. Am. 78, 2089-2097

Thouvenot, F., J. Fréchet, F. Guyoton, R. Guiguet and L. Jenatton (1990). Sismalp: an automatic phone-interrogated seismic network for the western Alps. Cahiers du Centre Européen de Géodynamique et de Séismologie 1, 1-10.

Thouvenot, F., J. Fréchet, L. Jenatton and J.-F. Gamond (2003). The Belledonne Border Fault: identification of an active seismic strike-slip fault in the western Alps. Geophysical Journal International 155, 174-192.

Thouvenot, F. and J. Fréchet (2006). Seismicity along the northwestern edge of the Adria microplate. In N. Pinter et al. (eds) The Adria Microplate: GPS Geodesy. Tectonics and Hazards, Nato Science Series 61, 335-349.

Tilling, R.I., R.Y. Koyanagi and R.T. Holcomb (1975). Rock-fall Seismicity-Correlation with Field Observations, Makaopuhi Crater, Kilauea Volcano, Hawaii. Journal of Research of the US Geological Survey 3, 345-361.

Trifunac, M.D. and A.G. Brady (1975). A study of the duration of strong earthquake ground motion. Bull. Seism. Soc. Am. 65, 581-626.

Uhrhammer, R. (1996). Yosemite rock fall of July 10, 1996, Seismol. Res. Let., 67,47-48. 
Weichert, D., R.B. Horner and S.G. Evans (1994). Seismic Signatures of Landslides - the 1990 Brenda Mine Collapse and the 1965 Hope Rockslides. Bull. Seism. Soc. Am. 84, 1523-1532.

Wieczorek, G., J. Snyder, J. Waitt, M. Morrissey, M. Uhrhammer, R. Harp, E. Norris, R. Bursik, M. Finewood (2000). The unusual air blast and dense sandy cloud triggered by the July 10 , 1996 rock fall at Happy Isles, Yosemite National Park, California, Geol. Soc. Am. Bull., 112, 75-85.

\section{Affiliation and address of authors}

Laboratoire de Géophysique Interne et Tectonophysique (LGIT-CNRS)

Université Joseph Fourier

Maison des Géosciences, BP 53

38041 Grenoble Cedex 9

France 